\title{
Recommendations for Hypersonic Boundary Layer Transition Flight Testing
}

\author{
Scott A. Berry ${ }^{*}$ \\ NASA Langley Research Center, Hampton, VA 23681 \\ Roger Kimmel ${ }^{\dagger}$ \\ Air Force Research Laboratory, WPAFB, OH 45433 \\ and \\ Eli Reshotko \\ Case Western Reserve University, Cleveland, OH, 44106
}

\begin{abstract}
Much has been learned about the physics underlying the transition process at supersonic and hypersonic speeds through years of analysis, experiment and computation. Generally, the application of this knowledge has been restricted to simple shapes like plates, cones and spherical bodies. However, flight reentry vehicles are in reality never simple. They typically are highly complex geometries flown at angle of attack so three-dimensional effects are very important, as are roughness effects due to surface features and/or ablation. This paper will review our present understanding of the physics of the transition process and look back at some of the recent flight test programs for their successes and failures. The goal of this paper is to develop rationale for new hypersonic boundary layer transition flight experiments. Motivations will be derived from both an inward look at what we believe constitutes a good flight test program as well as an outward review of the goals and objectives of some recent US based unclassified proposals and programs. As part of our recommendations, this paper will address the need for careful experimental work as per the guidelines enunciated years ago by the U.S. Transition Study Group. Following these guidelines is essential to obtaining reliable, usable data for allowing refinement of transition estimation techniques.
\end{abstract}

\section{Introduction}

$\mathrm{F}$ UTURE designs of space transportation systems, such as the next generation "Shuttle", "Apollo", or even a scramjet powered transport (e.g., NASP), will be heavily dependent upon prediction and knowledge of where, when, and how boundary layer transition (BLT) will occur during atmospheric transit, specifically during the hypersonic portion of the trajectory. ${ }^{1}$ The reason for this is that boundary layer turbulence can increase surface heating by fivefold, or more, over laminar levels and thus has a significant impact on the choice of the vehicle's thermal protection system (TPS) if transition is expected at high hypersonic speeds. From the dawning of the "hypersonic era" (first starting with the ballistic missile systems of the early 1950's), BLT researchers have struggled to understand the transition process with the hopes of someday enabling a physics-based predictive capability that is applicable to all configurations. Advancements have come at a painstakingly slow pace with only occasional, incremental breakthroughs in our understanding and modeling of the physical processes, proving that BLT is a tough nut to crack. A goal worthy of continued investment and research, the "universal" BLT prediction tool would allow reduced design-cycle times for all future programs.

The basis of modern day research, scientific method dictates that observable, empirical and measurable evidence of behavior must be utilized for acquiring knowledge and revising theories. For aeronautics, wind tunnels have been the primary source for scientific advancements made over the years, a tradition first started by the Wright Brothers. For unraveling the mysteries BLT processes at supersonic and hypersonic speeds, conventional tunnels turn out to

\footnotetext{
* Aerospace Engineer, Aerothermodynamics Branch, m/s 408a, Associate Fellow AIAA.

${ }^{\dagger}$ Principal Aerospace Engineer, Associate Fellow AIAA.

† Kent H. Smith Professor Emeritus of Engineering, Fellow AIAA.
}

1

American Institute of Aeronautics and Astronautics 
be largely unsatisfactory because of contamination that occurs due to "noise" radiating from turbulent boundary layers on the tunnel walls onto the model. The model contamination leads to distorted observations of transition that cannot be a true representation of the expected behavior at flight conditions. The "tunnel noise" issue led to the development of quiet tunnels, those that maintain laminar boundary layers on the tunnel walls downstream of the nozzle throat for sufficient distance so that there is a significant "quiet" zone for stability and transition studies. Unfortunately, the roster of quiet tunnels is sparse. There is the Mach 3.5 Pilot Quiet Tunnel at NASA Langley, the Purdue University Ludwieg tube facilities at Mach 4 and 6, and the former NASA Langley Mach 6 quiet tunnel now installed and operating at Texas A\&M University. These facilities can be operated in both quiet and noisy modes depending on whether the throat bleed slots are open or closed. In most instances, when operating in the quiet mode, these tunnels aren't long enough to experience transition on the model, nor can they generate conditions truly representative of hypersonic flight.

Therefore, the only realistic alternative for allowing fundamental breakthroughs in our understanding of the transition process at hypersonic flight conditions is flight-testing. While aircraft have been used as testing platforms for transition studies up to Mach 2, there are no aircraft available for hypersonic testing (with the exception of the Shuttle, which will soon be retired). Past hypersonic BLT flight studies have relied on rockets to reach test conditions and this is likely the case for future studies as well. Carrying out such studies has involved overcoming formidable challenges in the design and instrumentation of the model to yield the desired data both for transition and the test conditions for each data point obtained, and telemetering the data to a receiving station for eventual analysis. Reference 2 provides a survey of published hypersonic flight data appropriate for studying the mechanisms of hypersonic boundary layer transition, which highlights some of the challenges with conducting flight tests.

This document is intended to provide recommendations for conducting a future hypersonic boundary layer transition flight test. Motivational themes will be derived from both an inward look at what we believe constitutes a good flight test program as well as an outward review of the goals and objectives of some of the recent U.S. based unclassified proposals and programs. To satisfy the stated objective, this paper will be developed as follows: Section II will review our present understanding of BLT processes in the context of motivation for future hypersonic transition research. Section III will examine recent U.S. hypersonic flight test programs. Section IV will provide some lessons learned with specific cases studies that illustrate both good and bad practices. Section V briefly assesses existing launch vehicles and their capabilities for use in future hypersonic boundary layer transition flight experiments. Section VI presents guidelines for transition testing based on the suggestions of the U.S. Transition Study Group. Finally, Section VII presents our recommendations for future hypersonic BLT flight experiments.

\section{Primary Drivers for Hypersonic Boundary Layer Transition}

In regards to a next-generation hypersonic vehicle, the design goal would be to maintain a laminar boundary layer for as long as possible in order to minimize heating and thus reduce TPS requirements. At hypersonic speeds, the boundary layer tends to thicken and, in general, become more resistant to disturbances. However, there are still many pathways to transition, even at very high Mach numbers. ${ }^{3}$ For instance, small perturbations to the boundary layer can excite various instability modes such as Tollmien-Schlichting (TS) waves ( $1^{\text {st }}$ and $2^{\text {nd }}$ modes), and crossflow (CF) or Goertler vortices. ${ }^{4}$ Furthermore, these instability modes can be modified or enhanced by receptivity of freestream disturbances, surface roughness (distributed and discrete), chemistry effects, ablation, and the non-linear interactions of all of the above. For flat, mostly two-dimensional surfaces, the TS waves tend to be the dominant instability, with the $2^{\text {nd }}$ mode most prevalent at higher Mach numbers. For three-dimensional surfaces, crossflow and Goertler instabilities can dominate. To better understand these transition mechanisms at hypersonic conditions, all of these factors should be studied in detail ${ }^{5}$ in a series of flight tests, each dedicated to one of the instability modes. Generally, an experiment should be designed to isolate a single factor to allow direct comparison with relevant theory. Sometimes this is not possible and so the interpretation of the results becomes more complicated. These issues will be further illustrated by the test programs described in the next section.

In many ways hypersonics represents the last frontier in aeronautics, as it is the flight regime that is the hardest and most expensive to deal with. Since the early 50's, national interests have dictated strong support for research and development in hypersonics and reentry heating. Much of this research has been sponsored by the Department of Defense, the Department of Energy, and/or NASA, with additional support from the aerospace industry and many universities. These same entities are potential present-day sponsors who would certainly benefit from a new flight experiment to better understand the physics of the transition process at hypersonic conditions. 


\section{Review of Recent Flight Test Programs}

Towards the goal of developing rationale and recommendations for a new hypersonic BLT flight experiment, the following section provides a review of the goals and objectives of some recent U.S. based unclassified proposals and programs. The time frame for this review is about the last 25 or so years, or about the time since the start of the National Aero-Space Plane (NASP) program. Note that in 1992 the Defense Science Board Task Force on NASP concluded that fundamental uncertainties in BLT (and other issues) were too great to recommend entering a fullscale X-30 flight demonstration program. Instead, the board recommended a smaller scale flight test program as a way to reduce uncertainties before proceeding again with another ambitious NASP-like program. In many ways, we are still waiting for that fundamental breakthrough in the field of hypersonic BLT to justify taking that next step. For an informative high-level review of all the major hypersonic flight projects, please see "The History of Hypersonics" by Hallion. ${ }^{6}$ The present paper attempts to "fill in the void" on BLT-related matters after Hallion's discussion on "Hypersonics in the Post-NASP Era."

The review of BLT flight experiments includes both unfunded proposals and funded programs. When appropriate, relevant lessons learned will also be presented in order to highlight areas for further investment and development. This discussion is intended to yield a backdrop for discussing key BLT issues worthy of a new flight program. The list below is not intended to be all-inclusive, instead highlighting only those proposals and programs that were largely unclassified and specifically targeting the acquisition of hypersonic BLT flight data. There are some recently flown programs (such as HyFly and X-51) not included here, as the flight results are not available to the open community. As a key to the sub-sections below, the programs that were successfully flown will have italicized sub-headings.

\section{A. HYFIRE 1988}

A series of 10 flights on various sounding rockets was proposed as the HYFIRE program in 1988 to study various hypersonic BLT issues (adverse pressure gradient on Goertler, $1^{\text {st }}$ and $2^{\text {nd }}$ modes, and CF) and aeroheating issues (atmospheric particulates, turbulent heating, and shock interactions). Details of the individual flights and corresponding objectives are listed in Table 1. HYFIRE was billed as an approach for filling the gap between hypersonic ground test capabilities and current testing needs. The approach was to utilize existing sounding rockets to boost experiments to the Mach and altitude shown in Fig. 1, to study key fluid physics problems of hypersonic airbreathing flight. Also shown in the figure (in grey) are the booster performance requirements targeted for these missions. Beyond the primary goal of providing hypersonic laminar boundary layer transition physics, these flights were also to enhance flight hardened instrumentation systems, improve knowledge of atmospheric flight environment effects, and build up operational capability for small-scale hypersonic flight research. The program was predicated on multiple flights to develop experience and strengthen results targeted at specific instability modes of interest. As noted in the table, half of the flights were to be on a 10-deg cone, providing redundancy if any inflight anomalies happened during the first few flights. Another flight was dedicated to allowing for direct comparison to existing wind tunnel data on the Stetson 14-deg cone model ${ }^{7}$. The first two flights were to be spin stabilized, while all subsequent flights were to include an active control system to provide tighter restraints on the test conditions for post-flight analysis.

Instrumentation requirements had begun to take shape for the early flights in the program. For instance, the first flight was to evaluate prototype high-frequency hot-film transition sensors, and test an on-board, realtime spectral analysis system, while obtaining pressure and temperature distributions and acoustic measurements. The second flight was supposed to build on the first with higher density instrumentation and use of a decelerator and aerial recovery system. Hellbaum and Garner ${ }^{8}$ provides details of the state-of-the-art instrumentation intended for this program. This multi-flight, multi-year proposal is estimated to have a price tag on the order of $\$ 50 \mathrm{M}$ (in FY88 dollars), although this figure is unconfirmed.

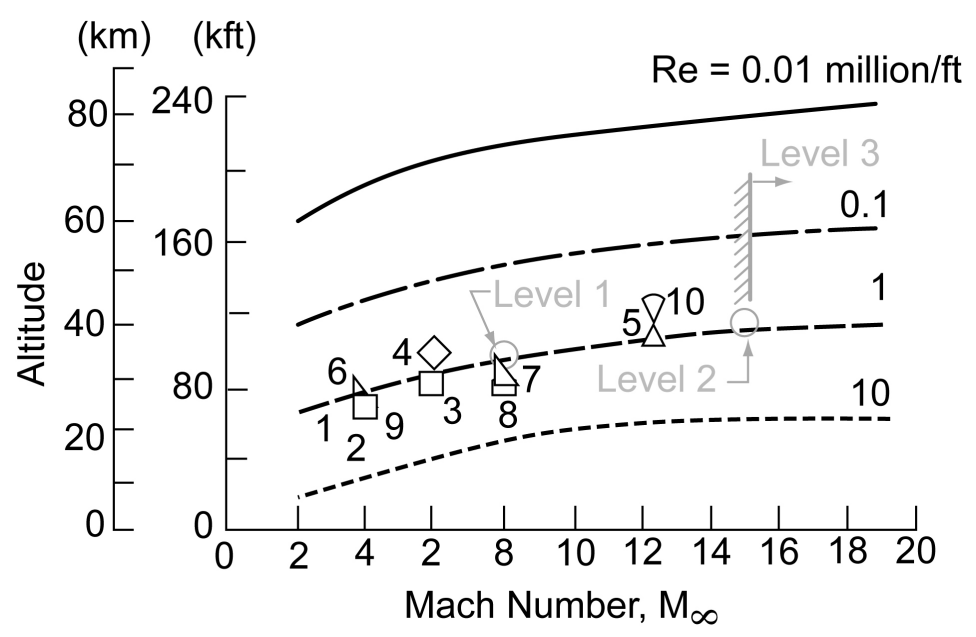

Figure 1. Operational scope of the HYFIRE program. 


\begin{tabular}{|c|c|c|c|c|c|c|c|}
\hline Flight & Payload & Objectives & Comments & $\begin{array}{c}\text { Altitude } \\
(\mathrm{kft})\end{array}$ & Mach & $\begin{array}{c}\mathrm{q} \\
(\mathrm{psf})\end{array}$ & Tstag (deg-F) \\
\hline 1 & $10^{\circ}$ Cone & Sys \& Ops Development & BLT data & 70 & 4 & 1050 & 1200 \\
\hline 2 & $10^{\circ}$ Cone & Sys \& Ops Development & BLT data & 70 & 4 & 1050 & 1200 \\
\hline 3 & $10^{\circ}$ Cone & Sys \& Ops Development & BLT data & 80 & 6 & 1475 & 2800 \\
\hline 4 & $10^{\circ}$ Cone & Atmospheric Particulates & BLT data & 100 & 6 & 600 & 2820 \\
\hline 5 & Bi-conic w/ Inlet & Turb Mixing \& Heating & Burning Effects & 100 & 12 & 2350 & SHARP* \\
\hline 6 & Concave Cone & Adv Press \& 1 $1^{\text {st }}$ Mode BLT & Gortler & 80 & 4 & 655 & 1210 \\
\hline 7 & $14^{\circ}$ Stetson Cone & $2^{\text {nd }}$ Mode BLT & Comp to WT & 92 & 8 & 1400 & $4150^{*}$ \\
\hline 8 & Concave Cone & Adv Press\& 2 ${ }^{\text {nd }}$ Mode BLT & Gortler & 80 & 8 & 2620 & $5256^{*}$ \\
\hline 9 & $10^{\circ}$ Cone & Atmospheric Particulates & BLT data & 70 & 4 & 1050 & 1200 \\
\hline 10 & Bi-conic w/ Inlet & Turb Mixing \& Heating & Burning Effects & 120 & $10-12$ & 1000 & SHARP* \\
\hline
\end{tabular}

Table 1. Details of the flights and objectives of the proposed HYFIRE program.

While this effort appears to be a well thought out proposal to advance the state of the art in understanding of BLT at hypersonic conditions, its timing was unfortunate with much of the available research budget being eventually absorbed by the NASP program in the early 90 's. This program reached a high level of maturity before cancellation, due to the availability of NASA base funding that enabled center management flexibility for allowing many researchers time to work on this proposal. In today's environment, program funding would be required for development of a new flight test effort of the maturity level of HYFIRE. Without discretionary or development funds at the research centers, an existing program would have to support early flight test proposal development in order to mature system level details required for establishing an accurate cost estimate.

\section{B. FLARE 1991 / HYFLEX 1992}

There were a number of studies during the first half of the 90's that looked into using the existing launch and flight capability at Sandia National Laboratories ${ }^{9}$ to conduct hypersonic flight experiments. One of these studies led to FLARE, which was proposed in 1991 to obtain BLT data with pressure gradient and cross-flow at Mach 15 and an altitude of $85 \mathrm{kft}$. The preliminary FLARE vehicle concept was a 14 - $\mathrm{ft}$ vehicle that had a 0.15 -in nose radius followed by a 5-deg cone that flared to 9-deg. The launch system was to be the Orbital Sciences' Pegasus booster and included plans for a parachute recovery system. In addition, secondary objectives included investigations of scramjet inlet cowl lip heating, shock-BL interactions, and internal flow separations with deployable inlets. As this proposal was based on a pre-existing flight program, surface instrumentation for this proposal was quite mature, with heat shield backside measurements using Sandia's standard thermal plugs, foil thermocouples, and radiometers. No details have thus far been found regarding unconventional or new instrumentation for high frequency information currently deemed vital to boundary layer research. Hand written notes taken during several planning meetings for this effort suggest that this program was on the order of $\$ 90 \mathrm{M}(\$ 30 \mathrm{M} / \mathrm{yr}$ spread out over three years), although this estimate has also not been verified. A memo from the program manager dated May 13, 1991 states that this flight program was contingent upon an augmentation to NASA's FY93 generic hypersonics budget, which ultimately did not materialize. Within a year, this proposal resurfaced as HYFLEX with identical goals and approach. In this case, the hope was a funding augmentation to the FY95 budget request (again, not funded). Additional details of the HYFLEX proposal can be found in Ref. 10.

\section{Pegasus Wing Glove Experiment 1992}

Another effort based on the Pegasus Launch Vehicle was proposed in 1992 called the Wing Glove Experiment (also discussed briefly in Ref. 10). The Pegasus wing-glove experiment successfully flew in October 1998 (after many years in storage waiting for a launch opportunity). ${ }^{11}$ The stated purpose for this flight test was to acquire $\mathrm{CF}$ data at approximately Mach 6 and 80-100 kft. This experiment was actually a secondary payload on a standard launch for a paying customer of the Orbital Sciences Pegasus launch vehicle, with a highly instrumented wing glove attached to the right side of the first-stage delta wing, as shown in Fig. 2. The glove was instrumented, as shown in Fig. 3, with surface pressure taps and backside thermocouples (type-K foil stick-on sensors). In addition, dynamic 
sensors (hot film and pressure transducers) were placed near the trailing edge of the glove in order to characterize the local flow fluctuations. Other instrumentation included a pressure rake, Preston tubes, and Stanton tubes. The total cost of the project was listed as \$10M (see Dryden News Release $98-75^{\S}$ ), the relatively low costs likely due to the piggyback arrangement with Orbital on a standard commercial launch.

Recently this data set was thoroughly analyzed and reported by Malik, et al. ${ }^{12}$ noting that "Contrary to the expectations based on pre-flight design computations, the glove boundary layer transitioned from

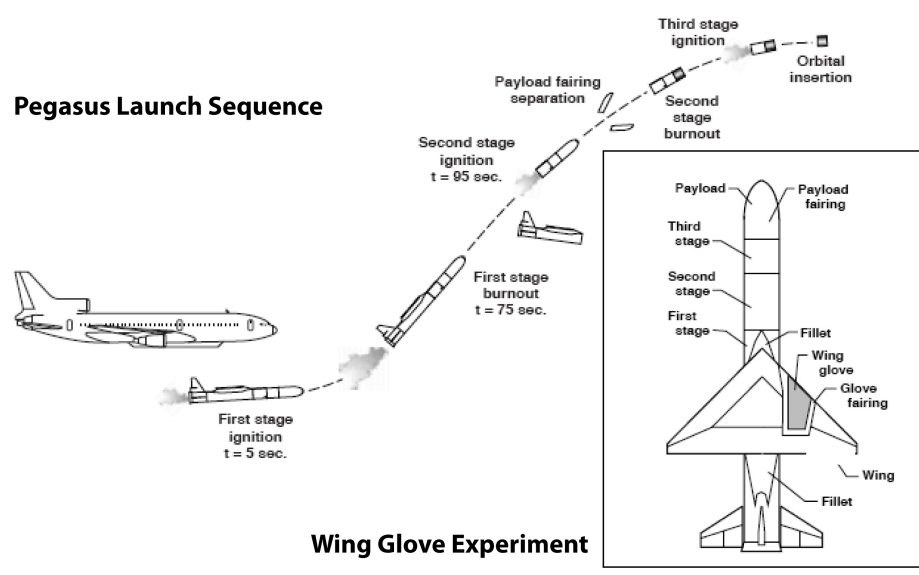

Figure 2. Pegasus launch sequence. turbulent to laminar at a Mach number of between 4 and 4.5 and was found to be completely laminar at the design Mach number of 6. Transition data on the much hotter inboard tile region are available up to about Mach 5.3." One explanation for this anomaly was that a higher unit Reynolds number had been erroneously assumed pre-flight than was actually obtained at the design Mach number for the experiment $\left(2.74 \times 10^{5} / \mathrm{ft}\right.$ pre-flight vs. $1.62 \times 10^{5} / \mathrm{ft}$ actual $)$.

Some comments based on observations derived from the post-flight analysis are provided next. The thermocouple data were fairly straight forward for interpretation of BLT movement on the thin-skin region of the steel glove and the insulated tile region outboard. However, the solid steel region used to construct the glove leading edge provided too much of a thermal mass to extract transition onset and movement. Therefore, attachmentline BLT data could not be identified from the flight data. (Although, it should be noted that attachment line transition was not a goal of the experiment.) In addition, the high frequency sensors ( 3 hot-film and 2 pressure transducers) that were employed on the glove provided transition times not fully consistent with the thermocouple data. The analysis showed that transition time determined from one of the hot-film sensors lagged that of the nearest thermocouple while the other hot-film sensor detected transition 2 seconds sooner than the nearest thermocouple in a different region of the glove. In both cases (thermocouple and hot-film), transition extent (time it takes for flow to transition from turbulent to laminar state at a given sensor location) was found to be about the same. Furthermore, not much useful information was obtained regarding boundary-layer disturbance frequencies in flight. Analysis of the experimental data did suggest that crossflow instability was present in this swept-wing boundary layer. Thus, this was the first in-flight demonstration of relevance of crossflow instability at Mach numbers above 4 . Comparison of the results from the cold glove and hot tile regions indicated that cross flow instability is stabilized due to wall cooling.

Due to the high frequency sensors, onboard processing of the data prior to telemetry was required. A significant issue with the Data Acquisition \& Processing System (DAPS) was the limited available bandwidth for the transfer of real-time data during the experiment window. This
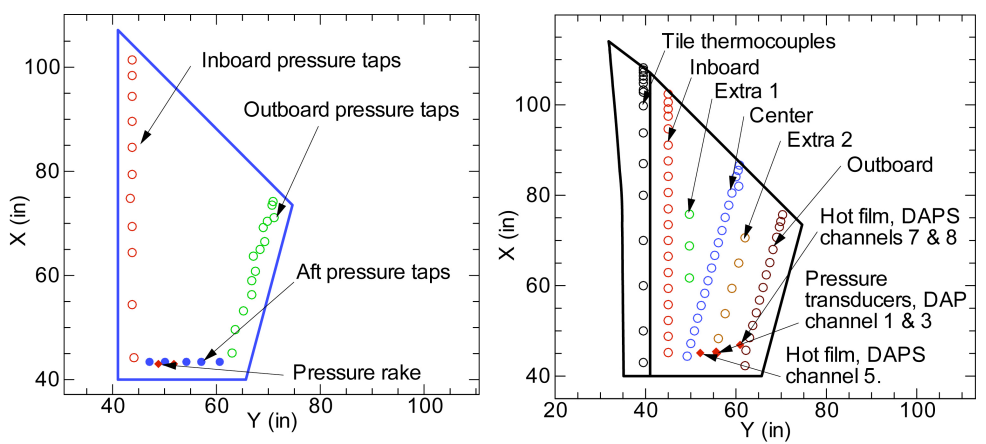

Figure 3. Pegasus wing-glove instrumentation. imposed a system requirement for data compression that allowed loss of some data. Thus, post flight decompression yielded data different from the original, although similar enough to still be useful. With today's technology, boundary layer data acquisition systems should no longer be subject to bandwidth issues while designed for lossless compression. In addition, any future DAPS should be required to undergo more pre-flight testing (in a wind tunnel or otherwise) to verify and validate that sensors and system were accurate and adaptable. With evolving design requirements and trajectories, the DAPS will need to be re-evaluated to insure that requirements will be met and then validation tested for any changes to the environment.

\footnotetext{
${ }^{\S}$ http://www.nasa.gov/centers/dryden/news/NewsReleases/1998/98-75.html
} 


\section{HYFLITE 1993}

After the demise of the NASP program came many proposals for hypersonic subscale airbreathing test vehicles. The HYFLITE (for Hypersonic Flight Test Experiment) flight project proposal was one of them, with multiple vehicles (up to 3) and flights (up to 7). The first vehicle was dedicated to BLT with isentropic compression and body flap on one side and flat 7.6-deg ramp followed by a flare on a 0.2 power law planform with control surfaces. The objective was to promote $2^{\text {nd }}$ mode waves with Goertler vortices on the compression side, but only $2^{\text {nd }}$ mode waves on the flat side. Vehicle pitch control was to be used to promote $\mathrm{CF}$ vortices along the sides. The second vehicle was dedicated to scramjet experiments, while the third was intended to be an unmanned $30 \%$ scale NASP-like vehicle. Initial plans called for the use of Minuteman 2 boosters for the first two vehicles, as shown in Fig. 4, while Titan 2 boosters were being considered for the third. As quoted in Aviation Week, ${ }^{13}$ "funding profiles of approximately $\$ 2 \mathrm{~B} / \mathrm{yr}$ for six years would be required to support construction and flight test of two X-30 demonstrators, and these funding levels were clearly unobtainable in the budget environment" of the time. The HYFLITE program was expected to "require perhaps $\$ 200-400 \mathrm{M} / \mathrm{yr}$ for the life of the program," which was thought to have a better chance of approval with the declining budgets for hypersonic research.

\section{E. HySTP 1994}

Even with an order of magnitude reduction for a proposed budget, HYFLITE was still not tenable with the climate at Capitol Hill. Thus, another try at restructuring a flight test program was attempted resulting in HySTP (for Hypersonic Systems Technology Program). The only stated goal of HySTP was to demonstrate positive acceleration with a scramjet experimental vehicle at Mach 15, thus the number of configurations (1) and launches (up to 4) was severely reduced. Both the scramjet design and vehicle shape were still to be determined based on trade studies between 3 notional configurations (as shown in Fig. 5): (1) an externalcompression inlet on a planar-symmetric
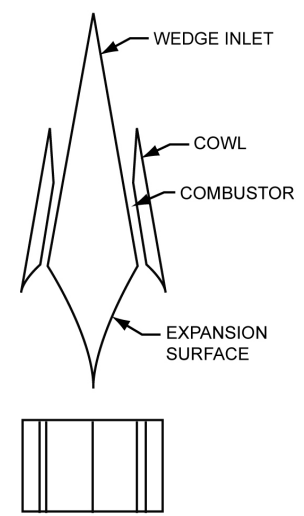
1). EXTERNAL COMPRESSION
PLANAR-SYMMETRIC
(WEDGE) INLET (WEDGE) INLET

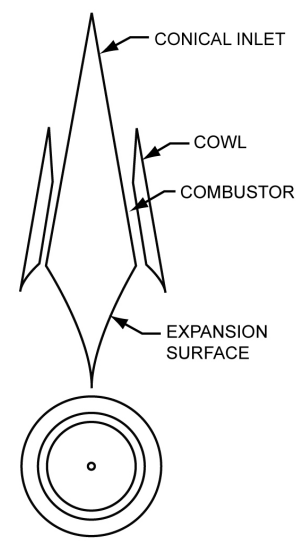

2). EXTERNAL COMPRESSION
AXI-SYMMETRIC AXI-SYMMETRIC
(CONICAL) INLET

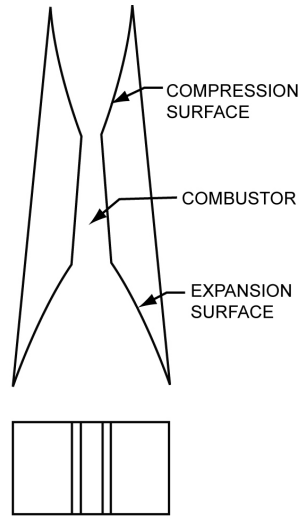

3). INTERNAL COMPRESSION PLANAR-SYMMETRIC INWARD-TURNING INLET
Figure 5. Notional HySTP configurations.

wedge design; (2) an external-compression inlet on an axi-symmetric (conical) design; and (3) an internalcompression inlet (inward-turning) on a planar-symmetric design (affectionately called "the gator"). (Note that later the planar wedge design was utilized with HyBoLT, the axi-symmetric inlet design was flown by the Russians ${ }^{14}$, and "the gator" design was included in the HIFiRE series.) Even the launch booster was to undergo a trade study with multiple variants of the Peacekeeper considered, see Fig. 6. Although BLT was not a stated goal with this proposed program, a ground test effort to understand and control BLT on a generic representation of the flight vehicle concepts had begun (see Ref 15). The primary thrust of this ground-based BLT effort was to develop the tripping mechanisms that would insure a turbulent BL for enhanced inlet performance. This effort was the precursor to a follow on Hyper-X trip development activity. Due to the relative immaturity of this program, flight instrumentation had not yet been defined. In the end, even this proposal was deemed too expensive at an estimated total cost of $\$ 450 \mathrm{M} .{ }^{16}$ 


\section{F. Hyper-X 1996}

After many unsuccessful proposals, a scramjet powered flight experiment called Hyper-X was finally approved and funded in $1996 .{ }^{17}$ Hyper-X, later designated X$43 \mathrm{~A}$, was primarily a scramjet experiment at Mach 7 and Mach 10 flight conditions, with BLT as a secondary concern, especially the effects of roughness or trips. ${ }^{18}$ Three flights were planned, but only two were successful. The Mach 7 vehicle was flown on Mar. 27, 2004 and the Mach 10 vehicle was flown on Nov. 16, 2004 (see Fig. 7). The Hyper-X research vehicles were $12 \mathrm{ft}$ long, weighed 2700-lb, and utilized a Pegasus XL to boost to proper flight conditions within the atmosphere. Smooth wall (on the upper surface) and roughness (on the inlet flowpath) BLT data was obtained on both flights, albeit with a limited instrumentation

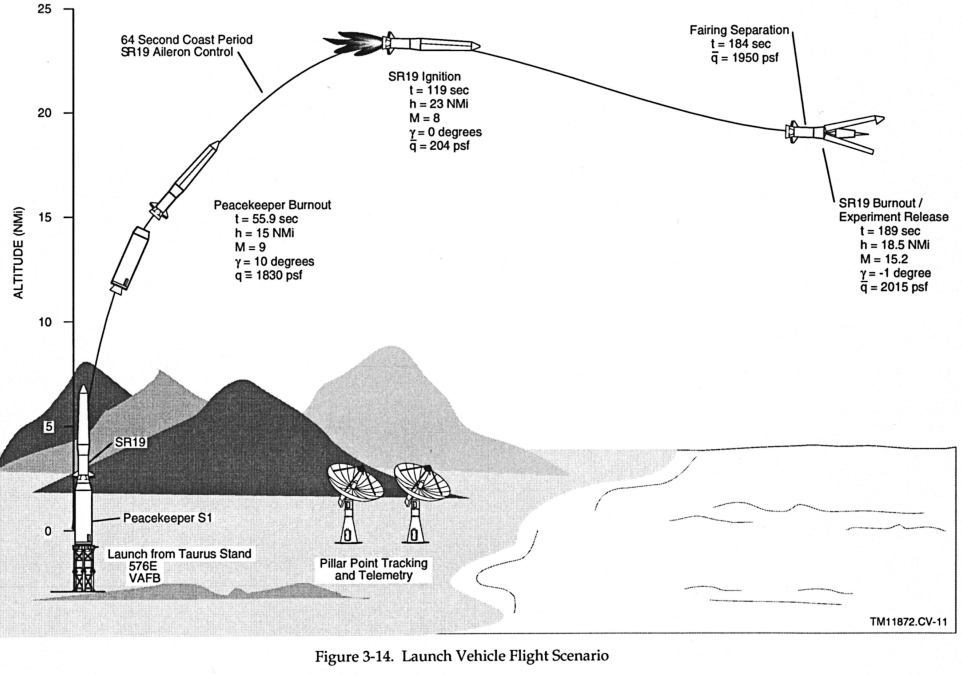

Figure 6. HySTP launch sequence.

array. The primary BLT measurement was from thermocouples (type-S) embedded just under the surface of Shuttle-like tiles. There was no other external instrumentation of interest to the BLT community. The Hyper-X program was initially projected to cost roughly $\$ 170 \mathrm{M}$, but cost overruns due to a stretch out of the program associated with the accident investigation of the first flight resulted in a final total budget of $\$ 230 \mathrm{M}$.

A report on a post-flight analysis of the BLT data from these flights is provided in Ref. 19. Both the upper surface (smooth) and lower surface (tripped) results behaved as expected based on the ground-based data and scaling for flight. The Shuttle-heritage thermocouples provided a relatively proven and robust flight measurement capability. The multiple flights allowed the program to overcome the first flight failure and still obtain repeatability data to verify results. The program also had a well-organized pre-flight ground-test program that did much to reduce instrumentation and flight control uncertainties. Although, one lesson-learned from this program is to think through the post flight analysis such that all pertinent data is acquired prior to flight. For both flight vehicles, key details of the thermocouple installation, such as local material properties and in-depth location, were never accurately obtained during vehicle assembly. In addition, most post-flight analysis and reporting were left unfunded after completion of the program. Since this was a scramjet flight experiment, primarily, no other BLT-centric instrumentation was utilized during these flights.

\section{G. HyTEx 2003}

This proposal was built around multiple flights (up to 7) using the Sandia vehicle (again) launched on various boosters (Talos-Terrier-Orion, STRYPI, and STARS) and was primarily dedicated to the maturation of advanced TPS concepts in support of the Next Generation Launch Technologies (NGLT). The stated

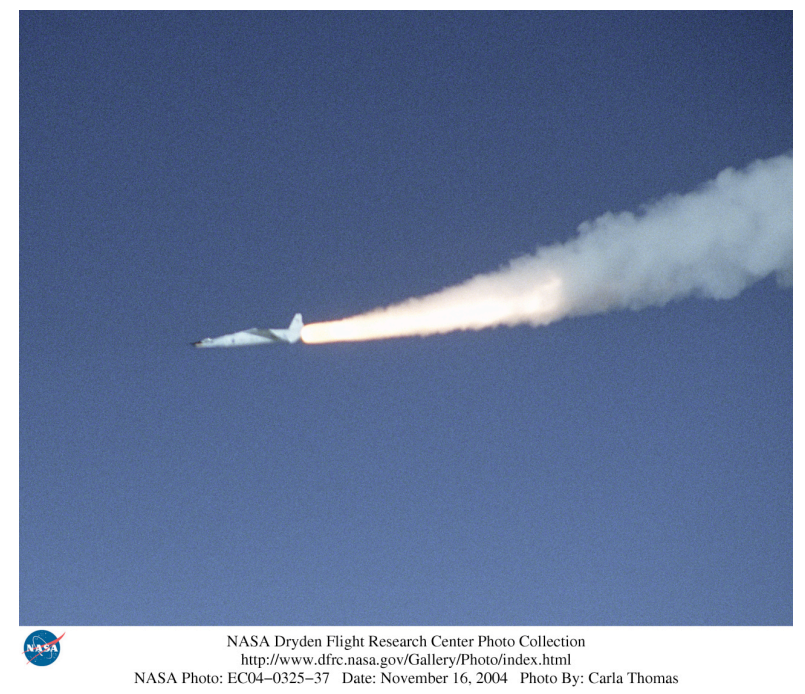

Figure 7. Successful Mach 10 flight of X-43A. objectives for this effort were as follows: ${ }^{20}$ demonstrate NGLT emerging technologies such as Thermal Protection System (TPS) performance with exposure to relevant re-entry heat loads, pressures, durations, and re-entry angles; demonstrate preliminary TPS operability characteristics; provide a means of demonstrating other secondary NGLT add-on and embedded technologies, as appropriate; demonstrate an approach for integrating re-entry technology experiments that maximizes the probability of obtaining data required to advance the technology readiness level; provide for recovery of the re-entry vehicle and associated technology experiments; provide appropriate flight instrumentation, provide real time flight telemetry data; and provide for fail-safe TPS experiments wherever 
possible. The total cost estimates for this proposal were in the range of $\$ 170 \mathrm{M}$. While this program was not primarily dedicated to BLT, it provided an opportunity to acquire many of the same measurements intended with previous proposals involving the Sandia flight vehicle. In all likelihood, the BLT data obtained during this test program would have been mostly roughness dominated from the various TPS samples flown.

\section{H. HyBoLT 2005}

The Hypersonic Boundary Layer Transition (HyBoLT) flight experiment was a quickly assembled "flight of opportunity" that resulted from cancellation of the SFX program. This was a single flight mission with two BLT-specific experiments (see Fig. 8 ), one smooth wall with $\mathrm{CF}$ along the outboard region and the other with trips in support of the Shuttle RTF BLT Tool ${ }^{21}$ intended to compare a cavity against protuberances. ${ }^{22}$ The test article was wedgelike with 12-deg (total angle) flat ramps (24in wide and 90 -in long) and 0.15 -in radius leading edge. The entire payload (experiment plus fairing) was 160-in long and weighed 2600 lbs. Launch was on a new one-of-a-kind ATK designed multi-stage booster. Data was

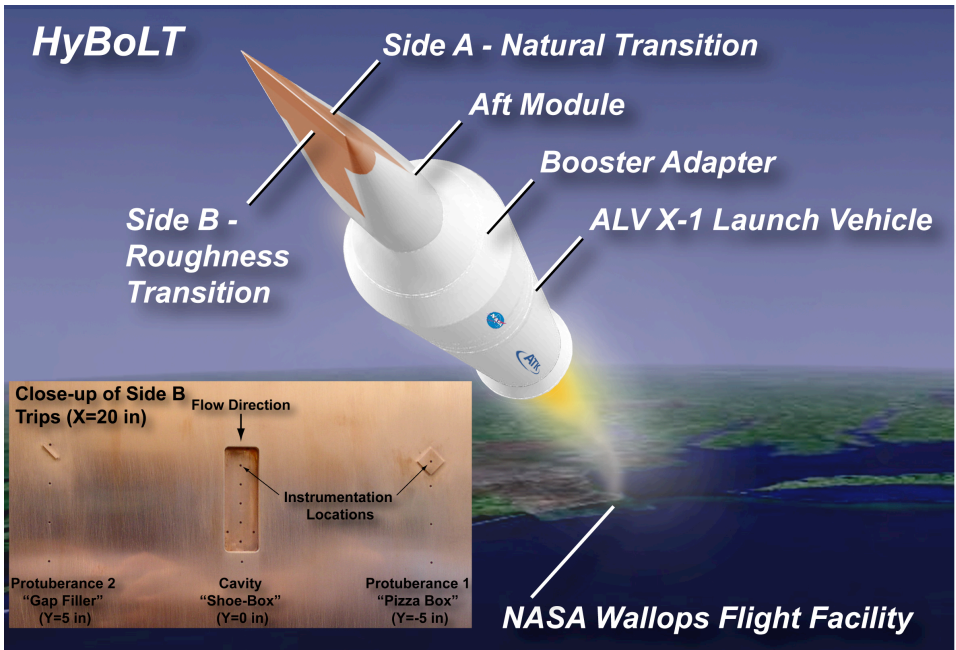

Figure 8. Notional HyBoLT launch.

to be obtained between Mach 5 and 7, and at 75 to $110 \mathrm{kft}$. Instrumentation included a high density of surface thermocouples to accurately map the movement of transition, high frequency thin film sensors, special designed CF sensors, boundary layer rakes, and freestream dynamic pressure probe. The vehicle also had a dedicated data acquisition and telemetry system that included on-board processing for compression of high-frequency content to allow all data to fit within telemetry bandwidth limits. The flight, on Aug. 22, 2008, was terminated early due to the booster deviating off-course after lift-off. NASA's investment into this program was estimated to be $\$ 17 \mathrm{M}$, which does not include the cost of the launch vehicle (considered as ATK proprietary data).

HyBoLT provides a few "lessons learned" to consider for future flight programs. The nature of this opportunity only provided for one flight, and with the failed launch meant no return on investment. An additional flight would have allowed for mitigation of a guidance and control system error during lift-off, which was identified during a mishap investigation. ${ }^{23}$ This program also suffered from a short development window, which meant there was insufficient time to qualify on-board instrumentation. Additionally, limited telemetry bandwidth dictated by the booster system required on-board processing and compression. A recent post flight assessment of the effort ${ }^{24}$ discusses many of these issues.

\section{Shuttle BLT Flight Experiment 2006}

In a similar vein, the Shuttle was identified as another flight of opportunity, or more precisely as an opportunity soon lost. ${ }^{25}$ A proposal for utilizing Shuttle reentries to acquire meaningful BLT data before the end of the program was deemed an acceptable risk, largely to reduce uncertainties with the on-orbit damage assessment effort that was initiated because of the Columbia accident investigation. During the first return-to-flight mission, STS-114, uncertainties with discrete roughness BLT prediction at very high Mach numbers led to the decision to conduct the first-ever repair of an orbiter in flight. ${ }^{26}$ This risky repair decision was not taken lightly, resulting in additional investment in further ground-based research, coupled with the flight test proposal. Thus, for the Boundary Layer Transition Flight Experiment (BLT FE) Project, a manufactured protuberance tile was installed on the port wing of Discovery on STS-119, STS-128, STS-131 and STS-133 and of Endeavour for STS-134. ${ }^{27}$ An incremental approach was utilized to increase the protuberance height after successful missions. STS-119 flew a 0.25-inch protuberance with a predicted BLT onset at Mach 15.4 (based on the Shuttle BLT Tool Version ${ }^{28}$ ). Both STS-128 and STS-131 flew 0.35-inch protuberances, with a predicted BLT onset of approximately Mach 17.4 and 17.2, respectively, and both STS-133 and STS-134 flew 0.50-inch protuberances with a predicted BLT onset of approximately Mach 19.5. Additional instrumentation was installed in order to obtain more spatially resolved measurements downstream of the protuberance. On Discovery, ten new thermocouples were located behind the trip for measurement of both the movement of boundary layer transition and the size of the resulting turbulent wedge. Endeavour was instrumented with only four new thermocouples. 
Comparisons of analytical predictions to the obtained flight data have shown that while BLT onset times have been accurately predicted using BLT Tool Version 2, predicted temperatures are significantly higher than measured, especially at higher Mach numbers. ${ }^{29}$ The reason for this discrepancy is currently unknown. Because of the rapid turn-around time required to meet the shuttle manifest schedule, heavy emphasis was placed on engineering analysis to ensure the flight data discrepancies did not mask risks to the TPS. The engineering analysis consisted of generating knockdown factors in heating that were then applied to the next BLT FE mission as part of the pre-flight certification analysis.

Additionally, an anomaly associated with the thermocouple performance, which had been seen on

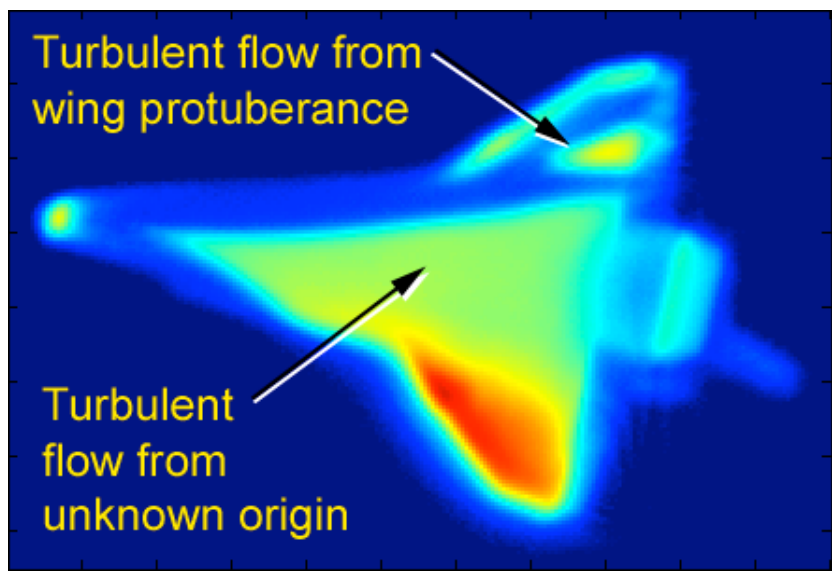

Figure 9. HYTHIRM image from STS-119 at Mach 8.4. previous shuttle missions, was noted to various degrees on all BLT FE flights. This anomaly is characterized by a rapid shift or offset in voltage readings. This behavior has been observed indiscriminately on some but not all thermocouple measurements (wing, fuselage, Orbital Maneuvering System pods). The cause for the measurement anomalies observed is unknown, though preliminary studies have shown a possible correlation with roll angle. Hypotheses being considered include Radio Frequency (RF) coupling due to the 'antenna' arrangement of the tile thermocouples, a direct voltage or current coupling flow to the thermocouple circuit, and a semi-conductor based Schottky diode effect. Because the anomaly general occurs at the first roll reversal, relatively early in the flight at high Mach number, it can affect the laminar data and prevent the collection of reliable maximum laminar temperatures. This anomaly has made further analysis and justification for flying larger protuberances difficult, which ultimately led to the decision to repeat the 0.35 -inch protuberance flown on STS-128 with STS-131.

Although the cause of the thermocouple anomaly is unknown, several actions are being taken on STS-134 in order to potentially mitigate the effects. These include wiring a thermocouple with a difference configuration (Sturn) and running all the FE thermocouples through a strain gage signal conditioner before going to the MADS PCM for better ground plane isolation. Additionally a flight rule has been approved that would delay roll reversals until after Mach 16, though this rule has been given a low priority in the shuttle program. As a result, it was not utilized on STS-133, the first flight for which it had been approved. An older flight rule protecting against roll reversals within \pm 1 Mach number from the expected BLT onset (for the trip) has been in effect for all flights. Details of the BLT FE program, including discussion of these discrepancies and mitigation strategies, can be found in Ref. 27. These anomalies point to the need for careful calibration of all instrumentation.

A $\$ 0.8 \mathrm{M}$ investment by NESC in 2007 was instrumental in initiating this effort. Additional work by Boeing was done to show the feasibility of safely utilizing a human rated operational vehicle to conduct flight research. The Shuttle program provided approximately $\$ 9 \mathrm{M}$ to allow for the implementation of the new instrumentation and for new protuberance tiles for the five flights. Relatively speaking, this flight test effort appears to be a significant bargain over all the other programs. However, it is important to keep in mind that the cost of each Orbiter flight is not included, so comparing costs is not apples-to-apples in this case.

Independent of the BLT FE, another project called Hypersonic Thermodynamic Infrared Measurements (HYTHIRM) has been responsible for obtaining in-flight thermal imagery of the Shuttle during reentry. ${ }^{30-36}$ Starting with STS-119 in March of 2009 and continuing through with a majority of the final flights, including all of the BLT FE flights, the HYTHIRM team has utilized a mix of airborne and ground based imaging platforms to view the Shuttle at hypersonic conditions. Each deployment of the HYTHIRM team has added to the collection of calibrated thermal imagery, at Mach numbers ranging from 8 to 18, suitable for processing and comparison with computational models and wind tunnel data. For STS-119, airborne imaging systems were utilized to capture the Orbiter at Mach 8.4, shown in Fig. 9. This figure provides compelling visual evidence of a turbulent wedge in flight at hypersonic conditions. The small turbulent wedge towards the top of the image is due to the BLT FE, while the larger one towards the bottom cannot be tied to a known trip site. At this relatively low Mach number, the background surface roughness of the tile steps and gaps is enough to move the transition far forward on the vehicle, reinforcing the point that this vehicle is roughness dominated for transition. Each attempt by the HYTHIRM team to deploy assets for an imaging campaign requires, on average, around $\$ 0.8 \mathrm{M}$, depending on the number of assets and the number of times that reentry is waved off (requiring a redeployment of assets and hence, additional flight hours) due to weather. 


\section{J. HIFiRE 2007}

The Hypersonic International Flight Research Experimentation (HIFiRE) program is a hypersonic flight test program executed by the Air Force Research Laboratory (AFRL) and the Australian Defence Science and Technology Organization (DSTO). ${ }^{37,38}$ Its purpose is to develop and validate technologies critical to next generation hypersonic aerospace systems. The philosophy of the HIFiRE program has been to identify and attack specific technology gaps in hypersonic flight. Preference is given to phenomena that are difficult to analyze computationally or with ground tests. The intent of the program is to characterize the technology as fully as possible with a program of coordinated ground tests and computations, culminating in a test flight. A goal of the program is to demonstrate a management philosophy of affordable flight testing by using demonstrated solid-rocket boosters and a risk-tolerant approach.

Of the 10 proposed flights in the program, two are devoted primarily to aerothermodynamic experiments, HIFiRE-1 and HIFiRE -5. HIFiRE-1 focused on transition on an axisymmetric body, and HIFiRE-5 will consider transition on a non-axisymmetric body. HIFiRE-1 was the first science flight of the HIFiRE series. The HIFiRE-1 mission is described in a prior publication. ${ }^{39}$ HIFiRE-1 launched 22 March 2010 at the Woomera Prohibited Area in South Australia. In addition to other experiments on board, the test gathered boundary layer transition data during ascent and reentry. Initial results are summarized in a companion paper. ${ }^{40}$ Prior to flight, the ground-test and computational portion of the HIFiRE-1 program created an extensive knowledge base regarding transition on axisymmetric bodies. This effort has been summarized in numerous prior publications. ${ }^{41-52}$ Generally, the HIFiRE1 flight seems to have been successful in demonstrating an affordable approach to boundary-layer transition flight testing.

Figure 10 shows the HIFiRE-1 payload. The payload consisted of a 7-deg half-angle cone with $2.5 \mathrm{~mm}(\sim 0.098$ in) radius tangent-sphere bluntness, followed by a cylinder and 33-deg flare. The cone was devoted to the BLT experiment and the flare to the Shock Boundary Layer Interaction (SBLI) experiment. The cylinder between the cone and flare acted as an isolator to reduce the influence of the SBLI experiment on the BLT experiment. The HIFiRE-1 fore-cone consisted of an aluminum shell $20 \mathrm{~mm}$ thick. The nose-tip of the cone consisted of a solid piece of TZM (titanium-zirconium-molybdenum) alloy $100 \mathrm{~mm}$ long. A coating of iridium $50 \mu \mathrm{m}$ thick acted as an oxidation barrier for the TZM nose. The nose-tip was coupled to the aluminum shell with a $100 \mathrm{~mm}$ long steel frustum and a $20 \mathrm{~mm}$ long stainless-steel joiner frustum. The aluminum shell provided significant heat-sink capability to protect instrumentation, and the steel frustum and joiner insulated the shell from the nose-tip and minimized axial conduction effects.

The launch vehicle for the HIFiRE-1 payload was a Terrier Mk70 booster-Improved Orion sustainer ${ }^{53}$ motor combination. The Terrier and Orion motors were sourced from surplus military ordnance used extensively in sounding rocket programs. This motor combination was chosen to minimize overall program costs and, based on past flight experience, to deliver a Mach number between seven and eight during the experiments. Total payload weight was $135 \mathrm{~kg}(\sim 297.6-\mathrm{lb})$ with an all-up flight segment weight of $1554 \mathrm{~kg}(3426-\mathrm{lb})$ and a total stack length of just over 9 meters $(\sim 354.3$-in).

The first-stage Terrier motor burned out and separated at approximately six seconds after takeoff. By design, the payload remained attached to the second-stage Orion throughout the trajectory. Booster and sustainer were passively spin-stabilized using fin cant on the individual stages to minimize trajectory dispersion. The objective of this approach was to reduce cost by eliminating a control system. Instead, the emphasis was on minimizing angle of attack, maximizing instrumentation bandwidth, and using post-flight analysis to extract as much meaningful data as possible from the flight. This approach does introduce questions about sensor response characteristics in comparison to the rate of vehicle spin when angle of attack is present. During ascent, the vehicle remained at less than an angle-ofattack of 1-deg. The entire reentry vehicle (payload plus second stage) was aerodynamically stable and self-oriented into a nose-first attitude during reentry upon achieving sufficient dynamic

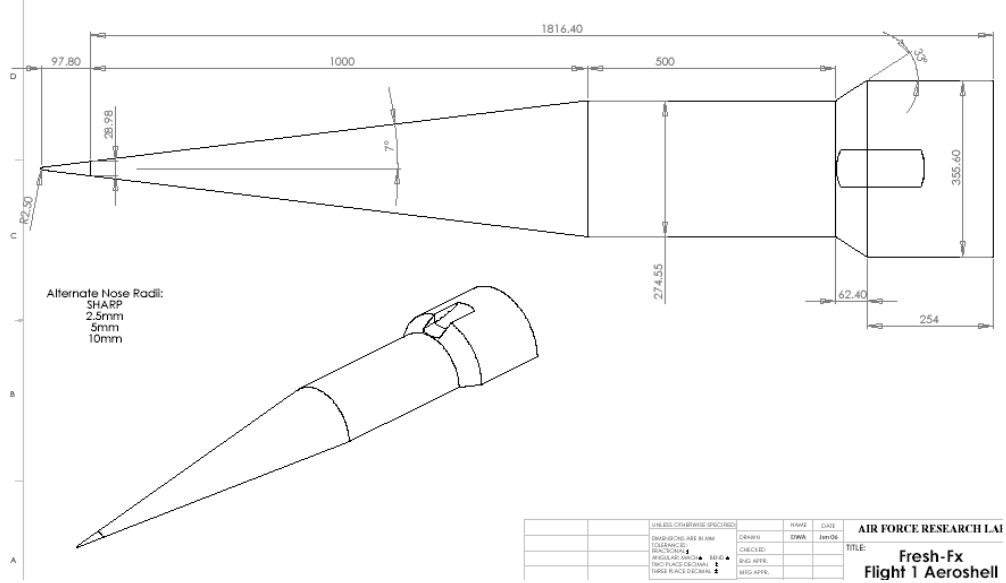

Figure 10. HIFiRE-1 payload. 
pressure. The payload remained in stable, nose-first flight to impact, obviating any recovery. In order to maximize reentry test time, it was intended that a cold-gas jet reaction control system would align the vehicle during exoatmospheric flight, so that the vehicle longitudinal axis was approximately coincident with the reentry flight path vector. The intent was to orient the vehicle at low angle of attack at the beginning of the test window, minimizing pitch oscillations during reentry. The reentry phase of the experiment was only partially successful, since the payload was at an angle-of-attack of 8-12 deg during reentry.

Although HIFiRE-1 delivered meaningful hypersonic transition data using a vehicle without active attitude control, in hindsight, some modifications would have improved data yield and quality. Interpretation of transition data from a spinning vehicle is difficult and requires relatively high bandwidth instrumentation. Differential thermal expansion from different materials at the vehicle tip required backward-facing steps that were designed to close up as the vehicle heated. These steps tripped the boundary layer immediately after launch. They might have been avoided if the vehicle had been designed to acquire data only on ascent, which probably would have obviated the need for refractory material in the nose-tip. Vehicle design was also complicated by the inclusion of secondary and tertiary experiments.

In addition to design issues described above, several mission failures occurred, most notably the GPS system and the exatmospheric pointing maneuver. These failures illustrate the importance of a multi-flight program. These issues will be addressed on the next transition flight in the HIFiRE series, HIFiRE-5, but currently there is no opportunity to fly a circular cone again in the HIFiRE program.

The HIFiRE-5 configuration consists of a payload mounted atop an S-30 first stage and Improved Orion $^{53}$ second stage motor. The test article consists of a blunt-nosed elliptic cone of 2:1 ellipticity, 0.86 meters in length. The payload does not separate from the second-stage Orion, and remains attached to it throughout the reentry. The vehicle is spin-stabilized in the same manner as HIFiRE-1. The elliptic cone configuration was chosen as the testarticle geometry based on extensive previous testing and analysis on elliptic cones. ${ }^{55-62}$ This prior work ${ }^{55-57}$ demonstrated that the 2:1 elliptic cone would generate significant crossflow instability at the flight conditions and potentially exhibit leading-edge transition. This flight is scheduled for November 2011.

There is no published information on the cost of each individual HIFiRE mission. However, an Aviation Week article suggested the entire effort as being $\$ 54$ million over the life of the program. ${ }^{63}$ While the original intent was for a multi-flight progression, only two of the ten flights were specifically targeted to address BLT issues.

\section{K. Programmatic Observations}

There are observations that can be made from the previous review of programs, both funded and not. An obvious one is to keep the costs of any new program low in order to enhance your chance of getting funding approval. Based on the programs reviewed here, and accounting for impact of inflation over the years, a threshold of roughly $\$ 100 \mathrm{M}$ appears to be good notional limit below which a program stands a better chance of finding a funding source. This threshold reflects a linear upward trend in time, the dashed line shown in Fig. 11, and does not account for year-to-year fluctuations in aeronautics support or specific outliers (like Hyper-X). Once approved, program success was enhanced in the specific cases where multiple flights were planned. Hyper-X is a good example of this, as the first flight failed and the second and third flights provided meaningful results. In contrast, HyBoLT provides an example of what can happen when you only have one opportunity to "get it right." As pointed out with the HIFiRE program, sounding rockets can be utilized to reduce costs, but compromises, such as the use of spin stabilization, may result. With spin stabilization, risk and complexity gets pushed downstream, from the flight-control system to instrumentation and post-flight analysis. One final observation not necessarily reflected in the previous discussions, but one that requires emphasis is the need to include in any plan some up-front work to qualify the proposed flight instrumentation. In most cases, the choices for instrumentation are not usually flight qualified for the needs of the program at hand.

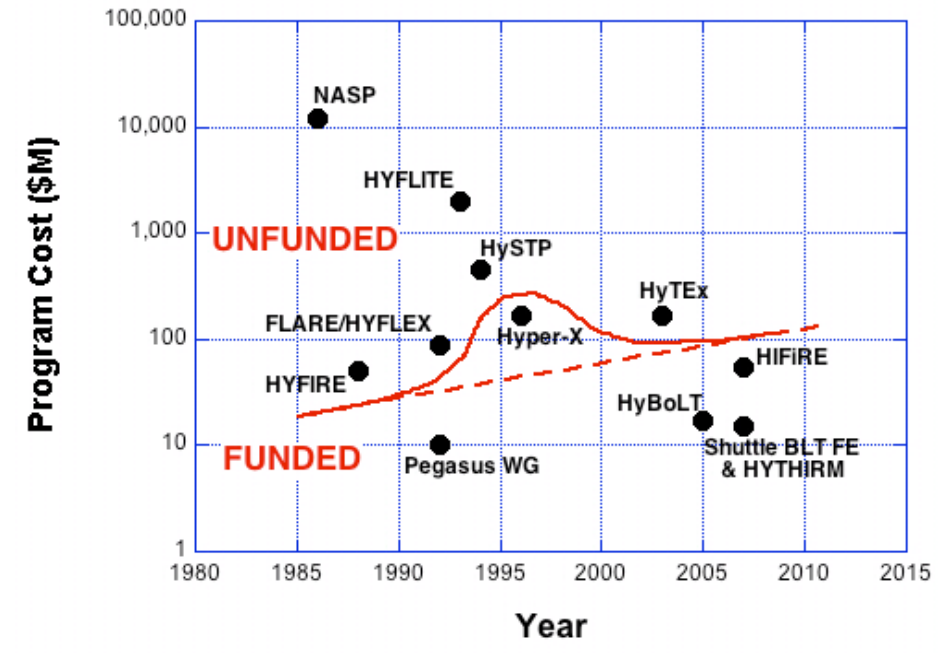

Figure 11. Review of published programs costs.

11

American Institute of Aeronautics and Astronautics 


\section{Additional Case Studies and Lessons Learned}

The following discussion is a personal review of various flight experiments by the third author, experienced through his Chairmanship for many years of the U.S. Transition Study Group. While the cases listed do not all strictly adhere to realm of hypersonics, they provide important lessons learned relevant to all flight experiments regardless of the speed regime.

\section{A. In-Flight Boundary-Layer Measurements on a Hollow Cylinder at a Mach Number of $3.03{ }^{64}$}

Objective: To obtain heat transfer and transition information for zero pressure gradient in flight at $\mathrm{M} \approx 3$.

The hollow cylinder was mounted about one diameter below the fuselage of a NASA YF-12 aircraft. The bottom of the aircraft fuselage was coated with a thick, rough gel (Fig. 12) "to protect the model from the aircraft and the aircraft from the model." The gel was rougher than any wind tunnel wall and surely radiated disturbances onto the model leading to early transition. In the end, this experiment did provide laminar and turbulent heat transfer rates but no useful transition information.

Lesson Learned: A researcher

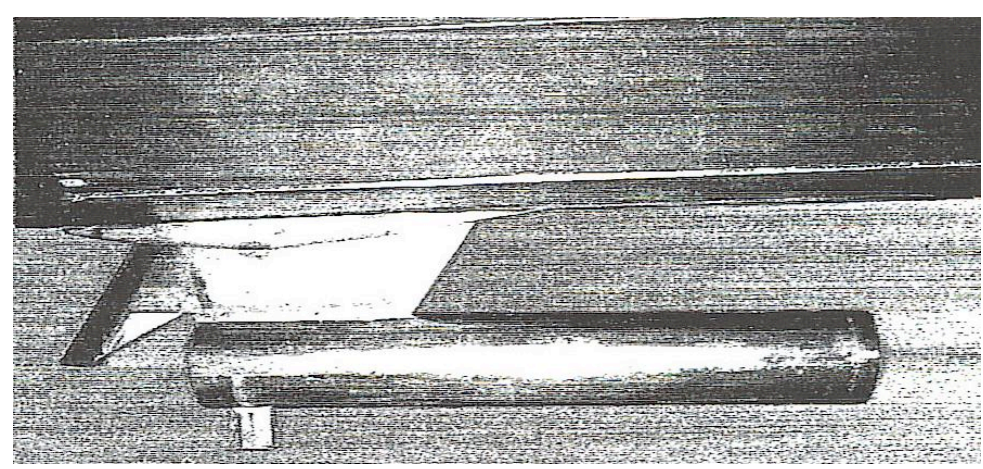
knowledgeable about transition physics should review installation issues in the design of the experiment.

\section{B. Transition Cone Flight Experiment ${ }^{65,66}$}

Objective: To use flight measurements of transition as a means of sorting out wind tunnel quality.

The model used was one that had been tested in many wind tunnels in the U.S. and elsewhere. The challenge here was to obtain wind tunnel quality data for each flight test point. To do this, the model was mounted in the clean flow ahead of the nose of the aircraft (Fig. 13). To implement the testing, the pilot/engineers made two important contributions. In cruise, the aircraft wing loading (W/S) is equal to the product of the lift coefficient, and the dynamic pressure. Since wing loading is more or less fixed, each angle-of attack of the aircraft corresponds to a specific dynamic pressure. However, since the model has to be at zero angle-of-attack and zero yaw, wedge spacers of half-degree increments were placed between the aircraft and the model, and flights were conducted at the combination of speeds and altitudes corresponding to a given dynamic pressure. The second item was to have the static pressure data from the pitot-static probe telemetered back to the aircraft and displayed on a special dashboard

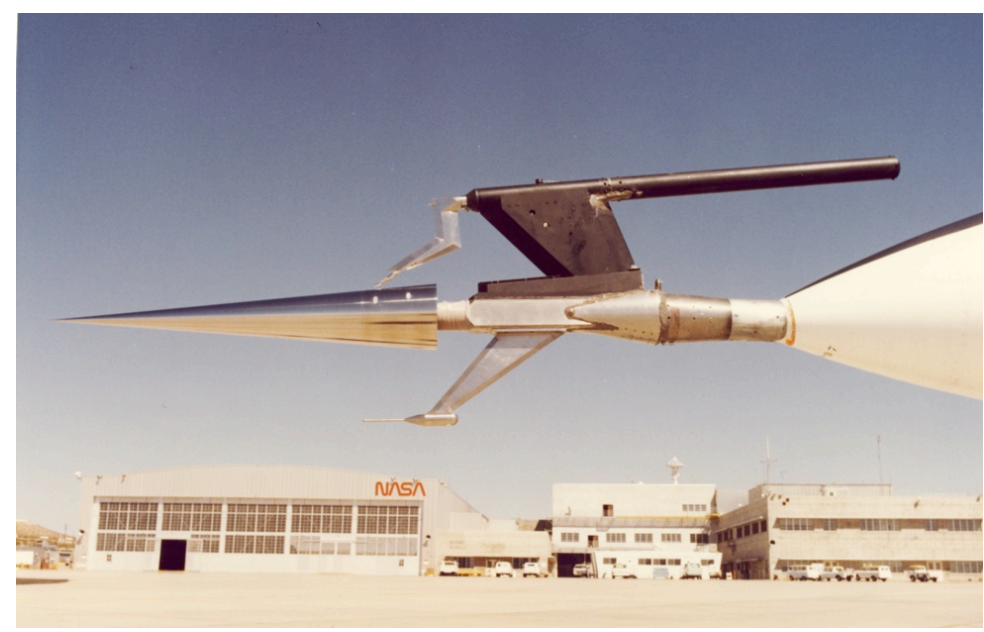

Fig. 13. Closeup photo of the cone flight experiment model

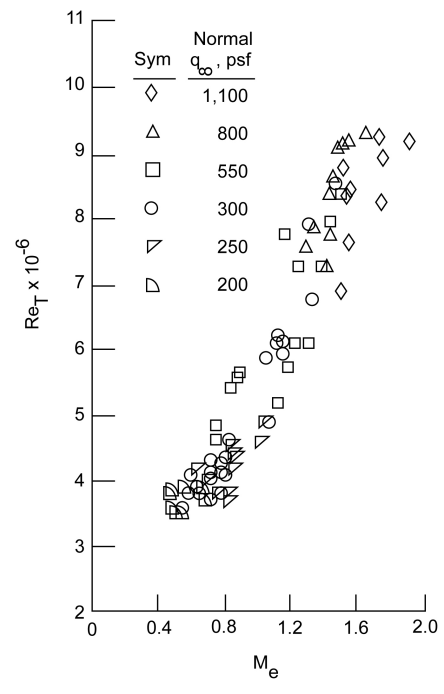

Fig. 14. In-flight transition Reynolds numbers as a function of $\mathrm{Me}$ 
meter that centered a bubble on crosshairs to indicate zero angle-ofattack and zero yaw. The pilot then had to maintain these conditions for the 30 seconds needed for a data point. The resulting data for each dynamic pressure are shown in Fig. 14. The comparison between the wind tunnel and flight data is shown in Fig. 15. The left figure shows the comparison for slotted wall transonic tunnels and solid wall supersonic tunnels. The right figure shows the comparison for perforated wall transonic tunnels. Another important transition region - beginning to end was much shorter in flight than in the wind tunnels (Fig. 16).

Lesson learned: Talk to the pilots!

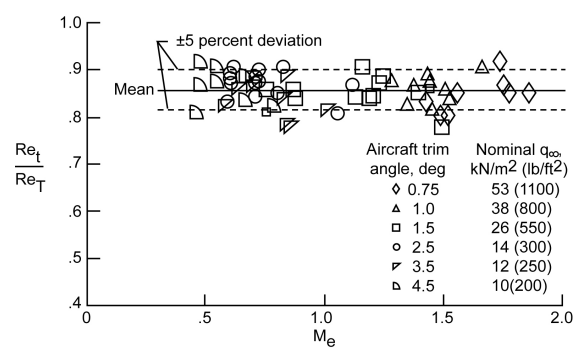
result was that the extent of the
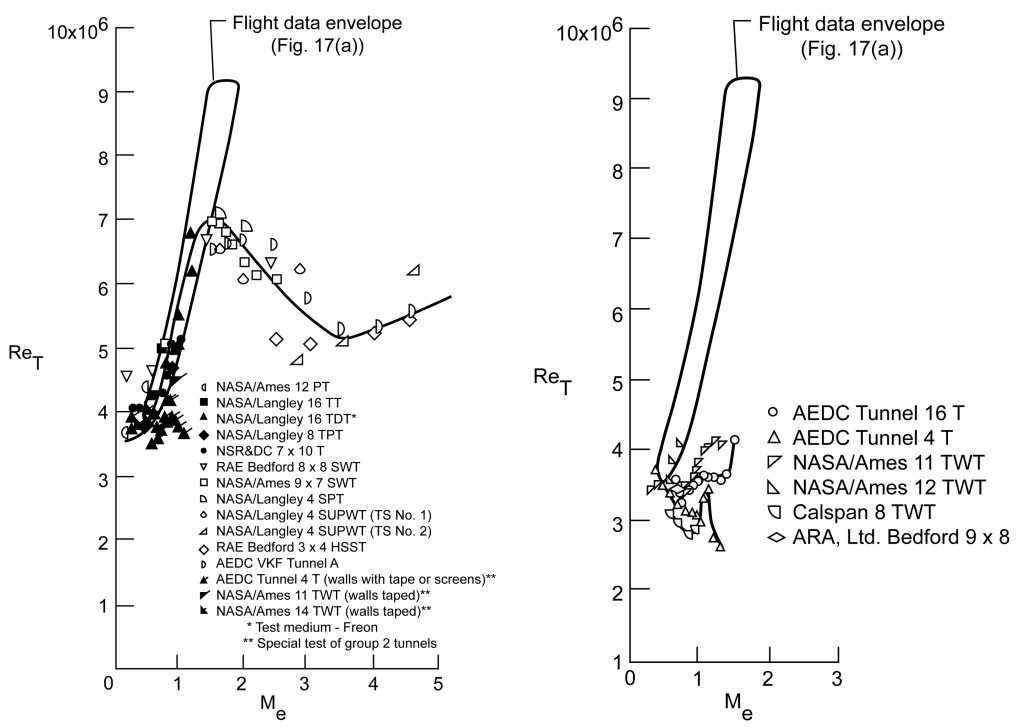

Fig. 15. Transition Reynolds Number Variation - Wind Tunnels vs. Flight

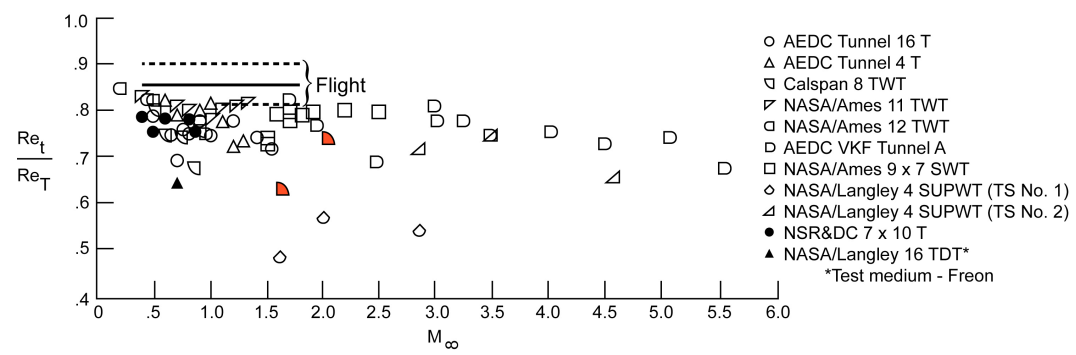

Fig. 16. Extent of Transition Region

\section{Swept Wing Model under F-15B ${ }^{67}$}

Objective: To study the ability to control crossflow instability in supersonic flight using discrete roughness elements.

The model mounting location is under the fuselage of the F-15B downstream of the engine inlets (Fig. 17). A view upstream from the test article location suggested that waves from the engine inlets would influence the flowfield in the region of the model. A subsequent Euler calculation of the aircraft flowfield showed that the flow in the vicinity of the model had a non-uniform droop so that the effective sweep angle varied along the span of the model. The calculations also showed that the pylon shock bled onto the model and was not cleared until the Mach number exceeded 1.8. The principal investigator was also denied the opportunity to place a probe near the trailing edge of the model to measure the unsteadiness level of the flow outside the boundary layer. While data were taken, they apply only to the model in its location and are difficult to interpret because of the nonuniformity of the oncoming flow.

Lesson Learned: A transition sensitive person should review installation issues in the design of the experiment.

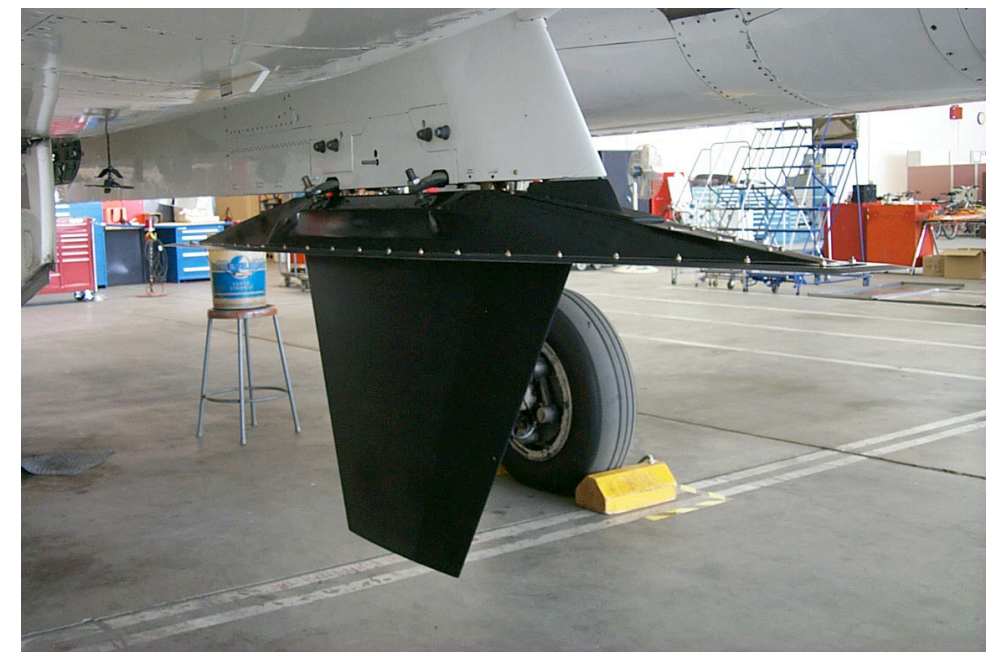

Fig. 17. Test Article under F-15B, $\Lambda=3^{\circ}$

13

American Institute of Aeronautics and Astronautics 


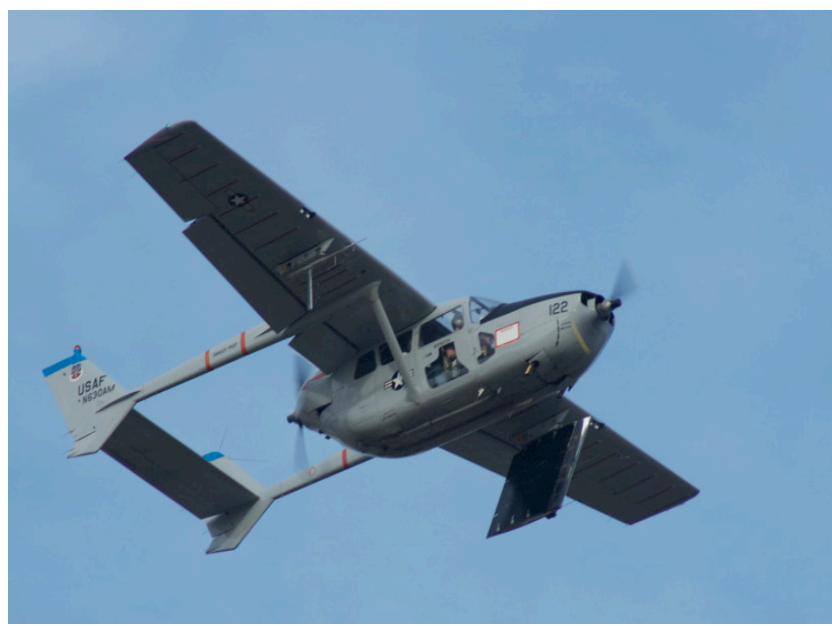

Fig. 18. Model mounting and initial pitot-static location on the Cessna 0-2 flight platform.

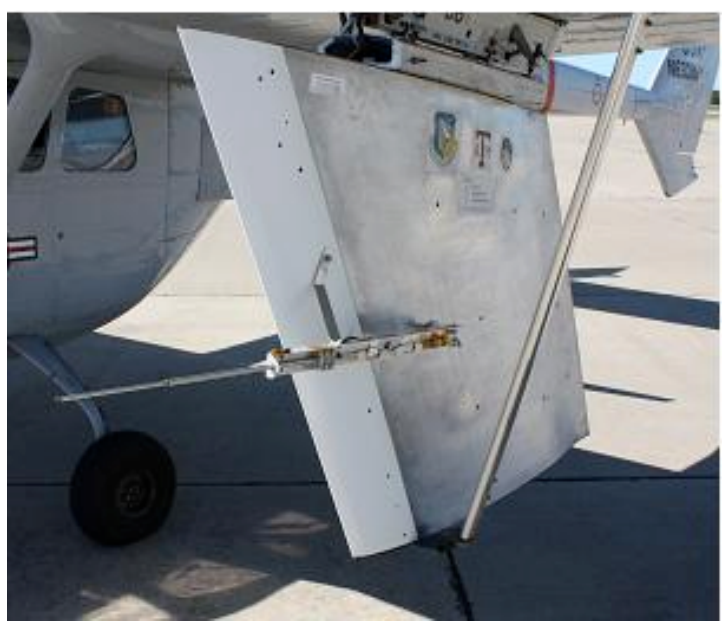

Fig. 19. Placement of the 5-hole probe on the model.

\section{Swept Wing Model on TAMU Cessna O-2A Aircraft}

Objective: To verify the effectiveness of discrete roughness elements in controlling crossflow instability in low speed flight.

In this case, the model is mounted below the port wing in a very clean oncoming flow. The flowfield information was obtained from a five-hole probe initially mounted in a symmetric location on the starboard wing (Fig. 18). With the model nominally at zero angle of attack according to the five-hole probe, the pressure distribution corresponded to $\alpha=-4^{\circ}$. This prompted a calculation of the aircraft flowfield (Rhodes, et. al. ${ }^{68)}$ which showed that the flowfield diverged from the centerline of the aircraft by $\pm 2^{\circ}$ at the model and probe locations. The solution was to place a five-hole probe on the model (Fig. 19) to measure the data for $\alpha, \beta, \mathrm{M}$ and Re (Carpenter, et. al. ${ }^{69}$ ).

Lessons learned: Don't make any assumptions about the vehicle flowfield. Maintenance and monitoring of test conditions such as speed, $\alpha, \beta$ and disturbance environment should be part of the test model.

\section{E. NACA Supersonic Flight Tests from Wallops Island, 1950s}

Objective: To obtain basic data on aerodynamic heating and transition at supersonic speeds.

These tests are associated the Rumsey and Lee group at NACA-Langley Aeronautical Laboratory and the Disher, Rabb, Krasnican group at the NACA-Lewis Flight Propulsion Laboratory and are described in the survey paper by Schneider ${ }^{70}$.

At the time of these flight tests, compressible boundary layer theory was in its infancy. Stability theory was hardly understood. This was before computers, before Les Mack, before second mode, etc. This was a well organized and well implemented program based on multiple flights, each one with a single objective! Some of the transition data are shown in the upper left section of Fig. 20. Even in the 1950's, it was recognized that there was a large, but not understood disparity between flight data and wind tunnel data. It was not until almost two decades later that it was recognized that transition behavior in conventional supersonic wind tunnels above $\mathrm{M}=2$ is dominantly due to the noise radiated onto the model from the turbulent boundary layers on the tunnel walls. A stability explanation for much of the data

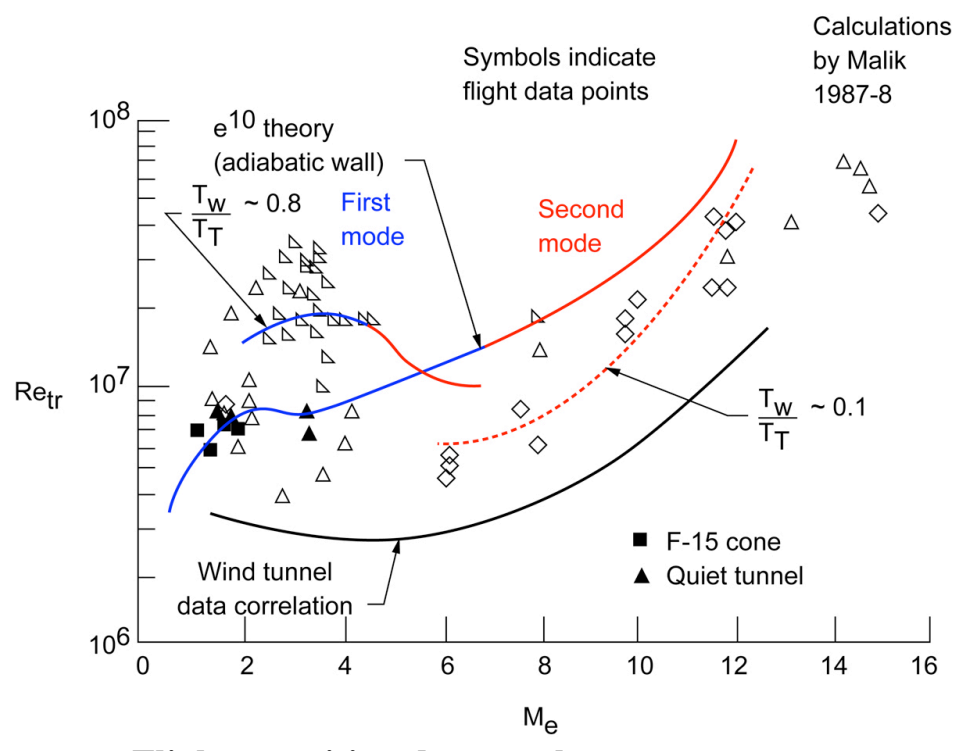

Fig. 20. Flight transition data on sharp cones. 
shown in Fig. 20 was provided in the late 1980's by Malik ${ }^{71}$.

Nevertheless, the laminar and turbulent heating data obtained were in agreement with theory, and lots of useful transition information was obtained before the time when it could be properly digested.

\section{F. Swept Wing Glove on Pegasus Vehicle ${ }^{11}$}

Objective: to provide crossflow transition data at high Mach numbers, specifically to help validate stability based predictions for transition onset in a flight environment.

This experiment is described in detail in Section IIIC and shown in Figs. 2 and 3. An issue prior to flight was the cleanliness of the vehicle upstream of the model. Another issue was the lack of funding for data analysis and interpretation for some years. Eventually such analysis was performed by Malik et al. ${ }^{12}$

Lessons learned: A transition sensitive person should review installation issues in the design of the experiment. Funding for data analysis and interpretation should be part of the program budget.

\section{G. Summary of lessons learned}

1. A proper flight experiment must have a clearly articulated objective, one that is not possible to realize in a ground based facility. It is best to have a single objective since multiple objectives cost more in money and time to design and often require compromises that diminish the ability to isolate results pertaining to a particular objective. Multiple objectives should be addressed in successive flights where each flight has a single objective.

2. Transition Study Group Guidelines are helpful. Follow them to the extent possible.

3. A transition sensitive person should review installation issues in the design of the experiment.

4. Don't make any assumptions about the vehicle flowfield. Maintenance and monitoring of test conditions such as speed, $\alpha, \beta$ and disturbance environment should be part of the test model.

5. Talk to the pilots! Although this lesson learned is not applicable to a rocket-based hypersonic flight test program, it does point to the need for careful consideration of your measurements. In the case of a hypersonic BLT flight experiment, instrumentation is the key to obtaining good data. Whenever possible, use instrumentation qualified for your flight environment.

6. Funding for data analysis and interpretation should be part of the program budget.

\section{Review of Existing Launch Capability}

A brief review of the existing rocket launch capability for conducting future hypersonic boundary layer transition flight experiments is now provided. Depending on the size of the experimental payload, either small sounding rockets or larger launch vehicles could be utilized for a future flight test. There are 11 operational launch vehicles in the NASA Sounding Rocket Program, see Fig. 21. These are all flown out of the Wallops Flight Facility (WFF), located on Virginia's Eastern Shore, of the Goddard Space Center. ${ }^{53}$ All of the sounding rockets flown by WFF are typically unguided (spin stabilized). In some cases, a flight control system can be added to these sounding rockets, mainly to reduce lift-off dispersions. These sounding rocket systems can typically handle payloads between $200-$ $1600 \mathrm{lbs}$ in a suborbital trajectory. There are other sounding rocket systems available; for instance, Sandia has the STRYPI class of vehicles that can be launched out of many locations (including WFF). For larger payloads (for instance, of a size similar to Hyper-X or HyBoLT), a larger launch vehicle would be required. There are a few options available, however launch costs would increase significantly with the size of the payload. Table 2 provides a comparison of some of the larger US launch systems available today in terms of ROM costs and payload size to low Earth orbit. The information listed in this table is notional and approximate, mostly assembled from on-line sources. Clearly, much of the capability listed here is excessive for most

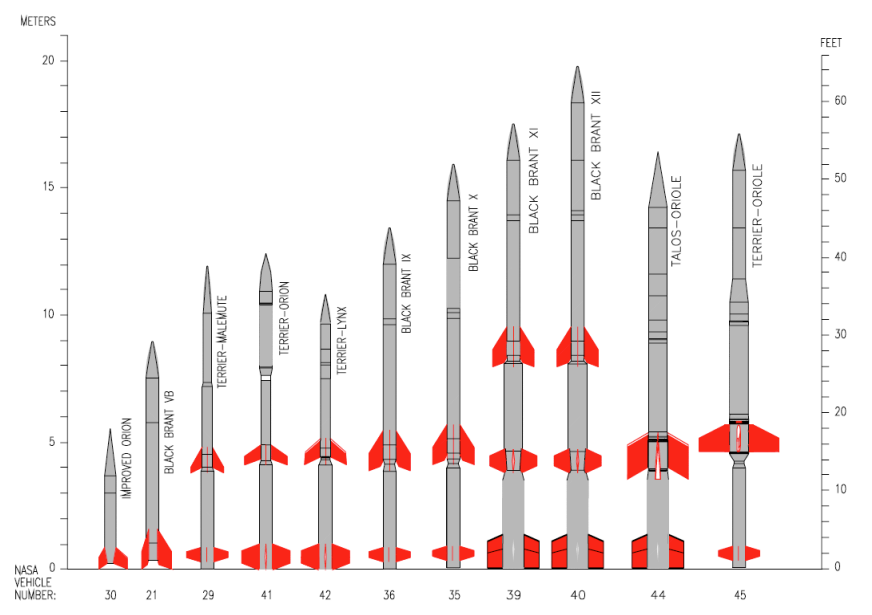

Figure 21. Advertised sounding rocket capability at Wallops. 


\begin{tabular}{|c|c|c|c|c|}
\hline Rocket & Source & Payload to LEO (lb) & Payload Diameter (ft) & $\begin{array}{c}\text { ROM Costs (adjusted } \\
\text { to 2009) }\end{array}$ \\
\hline Atlas V & LM & 27,500 & 12.5 & $\$ 155 \mathrm{M}$ \\
\hline Delta II & Boeing & 13,400 & 10 & $\$ 77 \mathrm{M}$ \\
\hline Delta IV Heavy & Boeing & 50,000 & 16.6 & $\$ 286 \mathrm{M}$ \\
\hline Falcon 1E & SpaceX & 2,000 & 5.5 & $\$ 11 \mathrm{M}$ \\
\hline Falcon 9 & SpaceX & 23,000 & 11.8 & $\$ 37 \mathrm{M}$ \\
\hline Minotaur & Orbital & 1410 & 5.5 & $\$ 16 \mathrm{M}$ \\
\hline Pegasus & Orbital & 826 & 4.2 & $\$ 15 \mathrm{M}$ \\
\hline Pegasus XL & Orbital & 976 & 4.2 & $\$ 16 \mathrm{M}$ \\
\hline STARS-C4 & Sandia & 750 & 4.5 & $\$ 14 \mathrm{M}$ \\
\hline Taurus & Orbital & 3,000 & 7.74 & $\$ 25 \mathrm{M}$ \\
\hline
\end{tabular}

Table 2. Larger launch vehicles currently available in the U.S.

scenarios for a future flight experiment proposal. In most cases, as with all the prior heritage cases described previously, a flight within the atmosphere, either through a sub-orbital or depressed trajectory, would be the most likely scenario. As an example, the Pegasus XL was utilized to boost a 2700-lb payload to both Mach 7 and 10 flight conditions for the Hyper-X program, which is roughly the same size payload that was used for the HyBoLT experiment. In terms of price, the cheapest options for a larger launch system are the Falcon $1 \mathrm{E}$ at roughly $\$ 11 \mathrm{M}$, the STARS-C4 at roughly $\$ 14 \mathrm{M}$, or the Pegasus XL at roughly $\$ 16 \mathrm{M}$. Of those three, the Pegasus XL stands out as the most proven and experienced system (35 successful launches out of 40, including the Wing-Glove Experiment and Hyper-X flights).

\section{Guidelines for Future Flight Experiments}

As pointed out previously, a proper flight experiment must have a clearly articulated objective, one that is not possible to realize in a ground based facility. It is best to have a single objective since multiple objectives cost more in money and time to design and often require compromises that diminish the ability to isolate results pertaining to a particular objective. Multiple objectives should be addressed in successive flights where each flight has a single objective, as exemplified by the earlier NACA-era and HYFIRE proposals. The standards for research quality experiments on stability and transition are the "guidelines" formulated by the U.S. Boundary Layer Transition Study Group ${ }^{72}$ :

1. Any effects specifically and only associated with the test facility characteristics must be identified and if possible avoided.

2. Attention must be given to disturbances introduced by the model surface, model material and internal structure. Experimental studies should include documentation of these various factors.

3. Details of coupling of disturbances of various kinds to the boundary layer must be understood theoretically and experimentally, so that the sensitivity to the flight environment might be determined.

4. Whenever possible, tests should involve more than one facility. Tests should have ranges of overlapping parameters, and whenever possible, experiments should have redundancy in transition measurements.

While developed primarily for wind tunnel studies, the above guidelines apply as well to flight experiments. Their implementation in flight experiments however requires special attention to a number of additional factors ${ }^{73}$ :

1. The measurement of disturbance environment must be incorporated into the model design and in fact must be part of the model.

2. Attention has to be given to the maintenance and monitoring of test conditions such as Mach number, Reynolds number, angle of attack, yaw angle and surface temperature for the duration of the measurement period.

3. Attention has to be given to the maintenance and monitoring of model surface conditions for each flight. This includes protection of the model surface before launch, and recovery of the vehicle for inspection and reconditioning of the surface prior to the succeeding flight. 
4. Because stability phenomena at supersonic and hypersonic speeds occur at frequencies of hundreds of $\mathrm{kHz}$ and even to $\mathrm{MHz}$ levels, there is a need for very high data sampling rates, especially when monitoring multiple channels. This poses special problems in data acquisition and data reduction. Reliable digital telemetering of data from the vehicle may also be necessary in order to minimize weight and volume of the data acquisition equipment.

\section{Recommendations for a Future Flight Program}

A recap of the successes to date, summarized earlier in the review of past programs, provides the backdrop for where to go next with a future hypersonic BLT flight experimental program:

1. NACA Sharp cones - demonstration of 1 st and 2nd mode transition via transition front movement and later comparison to theory

2. Pegasus $\mathrm{WG}$ - first in-flight demonstration of crossflow above Mach 4

3. Hyper-X - demonstrated boundary layer trips up to Mach 10 with "smooth" data in agreement with engineering predictions

4. Shuttle BLT FE - protuberance tripping up to Mach 19 in agreement with the BLT Tool

5. HIFiRE - demonstrated second-mode transition data on a circular cone at low Mach (approximately 5.2) and angle of attack (less than one degree)

Moving forward, the following recommendations for in-flight measurements, to allow further assessment of the physical mechanisms of hypersonic BLT, include: 2nd mode instabilities at Mach numbers above 6, CF data above Mach 5, Goertler data, quantifiable distributed roughness data, chemistry data, and ablation data. While it is likely that some of these data already exist, none are currently available in the open literature.

After careful consideration of the current needs of the hypersonic boundary layer transition community, with an eye on the goals, approaches, and lessons learned from past programs, we have formulated the following recommendations. The next hypersonic BLT flight program should consist of multiple flights, a minimum of 3 is preferred to allow for both redundancy and growth, while at the same time protect against any launch failures. Each subsequent flight should be considered as primarily a repeat of the last, to provide for a statistical basis for results obtained, although instrumentation development may have to be assumed as part of the multi-flight effort as flight qualification of sensors can be hard to do in ground-based facilities. In terms of a recommendation for the instability mode to address with the next program, the second mode instabilities are currently not well characterized in flight and should be measurable with current high-frequency sensor technology, such as surface mounted piezoelectric pressure gauges. Flight conditions in the range of Mach 6 to 10 and altitudes around 80kft should be adequate for an initial effort and will allow for some limited comparisons against ground-based data. These flight conditions can be easily obtained with current launch capability, both large and small.

In regards to this last point, no specific recommendations are provided in terms of the size of the payload, the preferred configuration, or which launch vehicle to utilize. These aspects will have to be addressed with a trade study that compares the size of the booster (and thus payload) against costs. To minimize costs, one could replicate the HIFiRE model where sounding rockets are utilized. This would restrict the size of the payload and introduce complications with the post flight analysis, if spin stabilization is used. Spin stabilization would also likely dictate an axisymmetric configuration. A multi-flight program using sounding rockets might be in the range of $\$ 15-30 \mathrm{M}$, depending on many variables. On the other extreme, a larger launch system, such as the Pegasus XL, could be utilized, which provides for larger payloads and better vehicle control, but with higher costs. A multi-flight program is likely to be in the range of $\$ 50-60 \mathrm{M}$. With the larger launch system, the configuration can be a three-dimensional shape, such as was used with HyBoLT or proposed for HYFLITE. Based on the Hyper-X example, we know that the Pegasus XL can provide for Mach 7 to 10 conditions for a 2700-1b payload flying a depressed trajectory.

With any flight program, it is further recommended that strict adherence to the guidelines, as listed earlier, be observed. The need for careful consideration of the vehicle surface conditions, both before and during the flight, is critically important to a flight test. Furthermore, it is recommended that redundant measurements of various test and flight conditions, such as freestream disturbances and vehicle attitude control, be considered.

Expanding on the near term recommendation, one could make a case for seeking similar data at flight conditions associated with higher Mach numbers to investigate gas chemistry effects on the measured instability modes. By extending the flight envelope to these higher Mach numbers, the next hypersonic BLT experiment would then be exploring flight conditions not obtainable in any ground test facility. 


\section{Acknowledgments}

The authors thank John Schmisseur of AFOSR, Douglas Dolvin of AFRL/RBA, Walt Rutledge of Sandia, Steve Schneider of Purdue University, Mujeeb Malik, Meelan Choudhari, Sharon Graves, Karen Berger, Tom Horvath, all of NASA, and Bruce Holmes, formerly of NASA, for their support of this work. The authors also wish to thank Mary Bedrick, Scott Stanfield, DSTO, AOSG, WSMR and the NASA/AFOSR National Hypersonic Science Center in Laminar-Turbulent Transition.

\section{References}

\footnotetext{
${ }^{1}$ Lin, T. C., "Influence of Laminar Boundary-Layer Transition on Entry Vehicle Designs," Journal of Spacecraft and Rockets, Vol. 45, No. 2, 2008, pp. 165-175.

${ }^{2}$ Schneider, S. P., "Flight Data for Boundary-Layer Transition at Hypersonic and Supersonic Speeds," Journal of Spacecraft and Rockets, Vol. 36, No.1, 1999, pp.8-20.

${ }^{3}$ Morkovin, MV, Reshotko, E and Herbert, T: "Transition in open flow systems - a reassessment," Bull. APS, vol. 39, no. 9, p. $1882,1994$.

${ }^{4}$ Reshotko, E., "Boundary Layer Instability, Transition, and Control,” AIAA Paper 94-0001, Jan. 1994.

5 Saric, WS, Reshotko, E. and Arnal, D.: "Hypersonic Laminar-Turbulent Transition," Hypersonic Experimental and Computational Capability, Improvement and Validation, Vol.2, AGARD AR-319, 1998, pp. 2-1 to 2-27

${ }^{6}$ Hallion, R. P., "The History of Hypersonics: or 'Back to the Future-Again and Again'," AIAA Paper 2005-0329, Jan. 2005.

7 Stetson, K.F., Thompson, E.R., Donaldson, J.C., and Siler, L.G., "Laminar Boundary Layer Stability Experiments on a Cone at Mach 8 - Part 1: Sharp Cone,” AIAA 83-1761, July 1983.

${ }^{8}$ Hellbaum, R. F., and Garner, H. D., "A Discussion of Some Proposed Measurement Techniques for Hypersonic Flight and Instrumentation Research Experiments," AIAA Paper 88-4651, Sept. 1988.

${ }^{9}$ Finnegan, P., "Mach 14 SWERVE Offers Potential of New Cruise Weapon,” Defense News, Mar 26, 1990.

${ }^{10}$ Blankson, I. M. amd Pyle, J. S., "NASA’s Hypersonic Flight Research Program,” AIAA Paper 93-0308, Jan. 1993.

${ }^{11}$ Bertelrud, A., de la Tova, G., Hamory,P., Young, R., Noffz, G., Dodson, M., Graves, S., Diamond, J., Bartlett, J., Noack, R., and Knoblock, D., "Pegasus Wing-Glove Experiment to Document Hypersonic Crossflow Transition - Measurement System and Selected Flight Results," AIAA Paper 2000-0505, Jan 2000.

${ }^{12}$ Malik, M. R., Li, F., Choudhari, M., "Analysis of Crossflow Transition Flight Experiment Aboard the Pegasus Launch Vehicle," AIAA Paper 2007-4487, June 2007.

${ }^{13}$ Kandebo, S. W., "NASP Cancelled, Program Redirected," Aviation Week and Space Technology, June 14, 1993, pp. 33-34.

${ }^{14}$ Roudakov, A. S. Semenov, V. L., and Hicks, J. W., "Recent Flight Test Results of the Joint CIAM- NASA Mach 6.5 Scramjet Flight Program," NASA/TP-1998-20654, Apr 1998.

${ }^{15}$ Holland, S. D., Berry, S. A., Weidner, J. P., and Dilley, A. D., "Design Methodology and Constraints for the Hypersonic Systems Technology Program (HySTP) Forebody/Inlet Model," NASA TM-110191, August 1995.

${ }^{16}$ Chase, R. L., and Tang, M. H., "A History of the NASP Program from the Formation of the Joint Program Office to the Termination of the HySTP Scramjet Performance Demonstration Program,” AIAA Paper 95-6031, Apr. 1995.

17 Rausch, V. L., McClinton, C. R., and Crawford, J. L., "HYPER-X: Flight Validation of Hypersonic Airbreathing Technology,” ISABE 97-7024, Sept. 1997.

${ }^{18}$ Berry, S. A., Auslender, A. H., Dilley, A. D., and Calleja, J. F., "Hypersonic Boundary-Layer Trip Development for Hyper-X," Journal of Spacecraft and Rockets, Vol. 38, No. 6, 2001, pp. 853-864.

${ }^{19}$ Berry, S., Daryabeigi, K., Wurster, K., and Bittner, R., "Boundary Layer Transition on X-43A," Journal of Spacecraft and Rockets, Vol. 47, No. 6, 2010, pp. 922-934.

${ }^{20}$ Bowles, D. E., and Barnes, R. S., "Next Generation Launch Technology, Vehicle Systems Research and Technology Project," AIAA Paper 2003-6945, Dec. 2003.

${ }^{21}$ Berry, S. A., Horvath, T. J., Greene, F. A., Kinder, G. R., and Wang, K. C., "Overview of Boundary Layer Transition Research in Support of Orbiter Return To Flight,” AIAA-2006-2918, June 2006.

${ }^{22}$ Berry, S., Chen, F., Wilder, M., and Reda, D., "Boundary Layer Transition Experiments in Support of the Hypersonics Program," AIAA-2007-4266, 39th AIAA Thermophysics Conference, Miami, FL, June 25-28, 2007.

${ }^{23}$ Norris, G., "Software Faulted In Failed Hypersonic Test," Aviation Week and Space Technology, Jan. 8, 2009.

${ }^{24}$ Chen, F-J and Berry, S. A., "HyBoLT Flight Experiment," NASA/TM-2010-216725, July 2010.

${ }^{25}$ Campbell, C.H., Garske, M.T., Kinder, G, and Berry, S.A. “Orbiter Entry Boundary Layer Flight Testing,” AIAA 2008635, January 2008.

${ }^{26}$ Berry, S. A., Horvath, T. J., Cassady, A., Kirk, B. S., Wang, K.C., and Hyatt, A. J., "Boundary Layer Transition Results From STS-114," AIAA-2006-2922, June 2006.

${ }^{27}$ Berger, K. T., Anderson, B., Campbell, C., Garske, M., Saucedo, M. Kinder, G., Micklos, A., "Boundary Layer Transition Flight Experiment Overview," AIAA Paper 2011-XXX, June 2011, paper pending.

${ }^{28}$ Berry, S. A., King, R., Kegerise, M., Wood, W., McGinley, C., Berger, K., Anderson, B., "Orbiter Boundary Layer Transition Prediction Tool Enhancements," AIAA-2010-0246, Jan. 4-7, 2010.
} 
${ }^{29}$ Anderson, B. P., Campbell, C. H, Saucedo, L. A., Kinder, G. R., Berger, K. T., "Boundary Layer Transition Flight Experiment Overview and In-Situ Measurements," AIAA 2010-240, Jan. 2010.

${ }^{30}$ Horvath, T., Berry, S., Alter, S., Blanchard, R., Schwartz, R., Ross, M., and Tack, S., "Shuttle Entry Imaging Using Infrared Thermography," AIAA-2007-4267, June 2007

${ }^{31}$ Horvath, T., Berry, S., Splinter, S., Daryabeigi, K., Wood, W., Schwartz, R., and Ross, M., “Assessment and Mission Planning Capability For Quantitative Aerothermodynamic Flight Measurements Using Remote Imaging," AIAA-2008-4022, June 2008.

${ }^{32}$ Berry, S., Horvath, T., Schwartz, R., Ross, M., Campbell, C., Anderson, B., "IR Imaging of Boundary Layer Transition Flight Experiments," AIAA-2008-4026, June 2008.

${ }^{33}$ Horvath, T. J., Tomek, D. M., Berger, K. T., Zalameda, J. N., Splinter, S. C., and Krasa, P. W., "The HYTHIRM Project: Flight Thermography of the Space Shuttle during Hypersonic Re-entry," AIAA Paper 2010-241, Jan. 2010.

34 Tack, S., Tomek, D. M., Horvath, T. J., Verstynen, H. A., and Shea, E. J., "Cast Glance Near Infrared Imaging Observations of the Space Shuttle during Hypersonic Re-entry," AIAA Paper 2010-243, Jan. 2010.

${ }^{35}$ Gibson, D. M., Spisz, T. S., Taylor, J. C., Zalameda, J. N., Horvath, T. J., Tomek, D. M., Tietjen, A. B., Tack, S., and Bush, B. C., "HYTHIRM Radiance Modeling and Image Analyses in Support of STS-119, STS-125, and STS-128 Space Shuttle Hypersonic Re-entries," AIAA Paper 2010-244, Jan. 2010.

${ }^{36}$ Zalameda, J. N., Horvath, T. J., Tomek, D. M., Tietjen, A. B., Gibson, D. M., Taylor, J. C., Tack, S., Bush, B. C., Mercer, C. D., and Shea, E. J., "Application of a Near Infrared Imaging System for Thermographic Imaging of the Space Shuttle during Hypersonic Re-entry," AIAA Paper 2010-245, Jan. 2010.

37 Dolvin, D. "Hypersonic International Flight Research and Experimentation (HIFiRE) Fundamental Science and Technology Development Strategy," AIAA Paper 2008-2581, April 2008.

38 Dolvin, D. J., "Hypersonic International Flight Research and Experimentation Technology Development and Flight Certification Strategy," AIAA Paper 2009-7228, October 2009.

39 Adamczak, D., Kimmel, and Brisbane DSTO-AVD Team, "HIFiRE-1 Flight Trajectory Estimation and Initial Experimental Results,” AIAA Paper 2011-2358, May 2011.

40 Kimmel, R. L., Adamczak, D., and Brisbane DSTO-AVD Team, "HIFiRE-1 Preliminary Aerothermodynamic Experiments," AIAA paper pending, June 2011.

${ }^{41}$ Kimmel, R. L., Adamczak, D., Gaitonde, D., Rougeux, A., Hayes, J. R., "HIFiRE-1 Boundary Layer Transition Experiment Design," AIAA Paper 2007-0534, January 2007.

${ }^{42}$ Wadhams, T. P., MacLean, M. G., Holden, M.S., and Mundy, E., "Pre-Flight Ground Testing of the Full-Scale FRESH FX-1 at Fully Duplicated Flight Conditions,” AIAA Paper 2007-4488, June 2007.

${ }^{43}$ Johnson, H. B., Alba, C. R., Candler, G. V., MacLean, M., Wadhams, T, and Holden, M. "Boundary Layer Stability Analysis of the Hypersonic International Flight Research Transition Experiments," AIAA Journal of Spacecraft and Rockets, vol. 45, no. 2, March-April 2008.

${ }^{44}$ Holden, M. S., Wadhams, T. P., MacLean, M., "Experimental Studies in the LENS Supersonic and Hypersonic Tunnels for Hypervelocity Vehicle Performance and Code Validation,” AIAA Paper 2008-2505, April 2008.

${ }^{45}$ Kimmel, R. L., “Aerothermal Design for the HIFiRE-1 Flight Vehicle,” AIAA Paper 2008-4034, June 2008.

${ }^{46}$ Casper, K. M., Wheaton, B. M., Johnson, H. B., and Schneider, S. P., "Effect of Freestream Noise on Roughness-Induced Transition at Mach 6," AIAA Paper 2008-4291 June 2008.

${ }^{47}$ Kimmel, R. L., "Roughness Considerations for the HIFiRE-1 Vehicle," AIAA Paper 2008-4293, June 2008.

${ }^{48}$ Alba, C. R., Johnson, H. B., Bartkowicz, M. D., Candler, G. V., and Berger, K. T. "Boundary-Layer Stability Calculations for the HIFiRE-1 Transition Experiment," AIAA Journal of Spacecraft and Rockets, vol. 45, no. 6, November-December 2008, pp. $1125-1133$.

49 Wadhams, T. P., Mundy, E., MacLean, M. G., and Holden, M. S., "Ground Test Studies of the HIFiRE-1 Transition Experiment Part1: Experimental Results," AIAA Journal of Spacecraft and Rockets, vol. 45, no. 6, November-December 2008, pp. 1134-1148.

${ }^{50}$ MacLean, M., Wadhams, T., Holden, M., and Johnson, H., "Ground Test Studies of the HIFiRE-1 Transition Experiment Part 2: Computational Analysis," AIAA Journal of Spacecraft and Rockets, vol. 45, no. 6, November-December 2008, pp. 11491164 .

${ }^{51}$ Berger, K. T., Greene, F. A., Kimmel, R. L., Alba, C., and Johnson, H., "Erratum on Aerothermodynamic Testing and Boundary-Layer Trip Sizing of the HIFiRE Flight 1 Vehicle," AIAA Journal of Spacecraft and Rockets, vol. 46, no., 2, MarchApril, 2009, pp. 473-480.

${ }^{52}$ Adamczak, D., Alesi, H., Frost, M., "HIFiRE-1: Payload Design, Manufacture, Ground Test, and Lessons Learned," AIAA Paper 2009-7294, October 2009.

53 "NASA Sounding Rocket Program Handbook," 810-HB-SRP, Sounding Rockets Program Office, Suborbital \& Special Orbital Projects Directorate, Goddard Space Flight Center, Wallops Island Flight Facility, June 2005.

${ }^{54}$ Palmerio, A. F.; Peres da Silva, J. P. C.; Turner, P.; Jung, W., "The development of the VSB-30 sounding rocket vehicle," in 16th ESA Symposium on European Rocket and Balloon Programmes and Related Research, 2 - 5 June 2003. Ed.: Barbara Warmbein. ESA SP-530, Noordwijk: ESA Publications Division, 2003, p. 137 - 140.

${ }^{55}$ Kimmel, R. L., and Poggie, J., "Transition on an Elliptic Cone at Mach 8," American Society of Mechanical Engineers ASME FEDSM97-3111, June 1997. 
${ }^{56}$ Kimmel, R. L., and Poggie, J., "Three-Dimensional Hypersonic Boundary Layer Stability and Transition," Air Force Research Laboratory Technical Report, WL-TR-97-3111, December 1997, Wright-Patterson Air Force Base, Ohio.

${ }^{57}$ Kimmel, R. L., and Poggie, J., Schwoerke, S. N., "Laminar-Turbulent Transition in a Mach 8 Elliptic Cone Flow," AIAA Journal, vol. 37, no. 9, Sep. 1999, pp. 1080-1087.

58 Schmisseur, J. D., "Receptivity of the Boundary Layer on a Mach-4 Elliptic Cone to Laser-Generated Localized Freestream Perturbations," Doctoral Dissertation, Purdue University Aerospace Sciences Laboratory, December 1997.

${ }^{59}$ Holden, M., "Experimental Studies of Laminar, Transitional, and Turbulent Hypersonic Flows Over Elliptic Cones at Angle of Attack," Air Force Office of Scientific Research Technical Report AFRL-SR-BL-TR-98-0142, Bolling Air Force Base, DC, 1998.

${ }^{60}$ Schmisseur, J. D., Schneider, S. P., and Collicott, S. H., "Receptivity of the Mach 4 Boundary Layer on an Elliptic Cone to Laser-Generated Localized Freestream Perturbations,” AIAA Paper 1998-0532, January 1998.

${ }^{61}$ Schmisseur, J. D., Schneider, S. P., and Collicott, S. H., "Response of the Mach 4 boundary layer on an elliptic cone to laser-generated freestream perturbations," AIAA Paper 1999-0410, January 1999.

${ }^{62}$ Lyttle, I. J., and Reed, H. L., "Use of Transition Correlations for Three-Dimensional Boundary Layers Within Hypersonic Flows," AIAA-95-2293, June 1995.

${ }^{63}$ Covault, C., "The HiFire Flight Tests Will Help Integrate Aeronautics and Space Technologies," Aviation Week and Space Technology, Mar 18, 2007.

${ }^{64}$ Quinn, R. D. and Gong, L. "In-Flight Measurements on a Hollow Cylinder at a Mach Number of 3," NASA TP-1764, Nov. 1980.

${ }^{65}$ Dougherty, N. S. Jr. and Fisher, D. F. "Boundary Layer Transition on a 10-Degree Cone: Wind Tunnel/Flight Data Correlation," AIAA-80-0154, January 1980.

${ }^{66}$ Fisher, D. F. and Dougherty, N. S. Jr. "In-Flight Transition Measurement on a 10-Deg. Cone at Mach Numbers from 0.5 to 2.0," NASA TP-1971, 1982.

${ }^{67}$ Saric, W. S., Reed, H. L., and Banks, D. W. "Flight Testing of Laminar Flow control in High Speed Boundary Layers," RTO-MP-AVT-111/RSM, 2005.

${ }^{68}$ Rhodes, R. G., Carpenter, A. L., Saric, W. S. and Reed, H. L., "CFD Analysis of Flight Test Configuration Flowfield and Laminarization of Swept Wing Boundary Layer with Flight Test Verification,” AIAA-2008-7336, 2008.

${ }^{69}$ Carpenter, A. L., Saric, W. S. and Reed, H. L., "In Flight Receptivity Experiments on a 30-degree Swept-Wing Using Micron-Sized Discrete Roughness Elements," AIAA-2009-0590, 2009.

${ }^{70}$ Schneider, S. P., "Flight Data for Boundary-Layer Transition at Hypersonic and Supersonic Speeds," Jour. Spacecraft and Rockets, vol. 36, No.1, 1999, pp.8-20.

${ }^{71}$ Malik, M. R., "Prediction and Control of Transition in Supersonic and Hypersonic Boundary Layers," AIAA J. Vol. 27, No. 11, 1989, pp. 1487-1493.

${ }_{72}$ Reshotko, E. "Boundary Layer Stability and Transition," Annual Review of Fluid Mechanics, Vol. 8, 1976, pp.311-349.

73 Reshotko, E. "Transition Research Using Flight Experiments" in Hussaini, M.Y. and Voigt, R.G., Instability and Transition Vol. I, Springer-Verlag, 1990, pp. 88-90. 